\title{
The Economics of Global Climate Change: A Historical Literature Review
}

\author{
Leo Dobes, Frank Jotzo, and David I. Stern ${ }^{1}$
}

\begin{abstract}
We review the literature on the economics of climate change with a focus on the evolution of the literature from some of the early classic papers to the latest contributions. We divide the paper into three main sections: trends in greenhouse gas emissions, mitigation, and adaptation.
\end{abstract}

Key Words: Climate change, economic development, mitigation, adaptation, policy

\section{JEL Codes: Q54}

Acknowledgements: Maximilian Auffhammer, Richard Carson, Douglas Patton, Kristen Schmitt, Jan Kunnas, and Max Kummerow provided helpful suggestions.

\section{Introduction}

Economic activity is a cause of climate change and climate change impacts economic activity. Governments, firms, and individuals are grappling with establishing policies to reduce emissions of the greenhouse gases that are causing the climate to change referred to as the mitigation of climate change - and facing up to the need to adapt to a climate that will change quite drastically whatever mitigation actions are taken.

Because the major greenhouse gases are long-lived and mix globally in the atmosphere, it does not matter in terms of climate change neither from where they are emitted nor in terms of mitigation where emissions are reduced. Therefore, climate change is a classic open access resource problem. Emitters impose damage globally and the benefits provided by abaters are shared by all. Climate change depends more on world economic activity than on economic activity in any one country and action on climate change requires global cooperation or at least coordination. Adaptation to

1 Crawford School of Public Policy, The Australian National University, 132 Lennox Crossing, Acton, ACT 2601, Australia. E-mail: david.stern@anu.edu.au. DAVID STERN is the corresponding author. All authors were involved in the writing of the paper but the section on trends was primarily written by DAVID STERN, the section on mitigation by Frank Jotzo, and the section on adaptation by Leo DoBes. 
climate change can occur locally, but involves a fundamental dilemma due to the uncertainty of the timing, intensity, and nature of future climate change. Non-optimal adaptation, aggregated across the globe, will have negative implications for growth and wellbeing for all countries.

Though policy concern about climate change first emerged in the late 1980s, scientific analysis of the greenhouse effect and human interference with it stretches back into the 19th Century. The economic literature originated in the 1970s with antecedents in the foundations of environmental economics reaching back into the 1930s. This paper provides a partial review of this literature, which emphasizes this fact that both the science and economics of anthropogenic climate change is not quite as new as some might think. This also allows us to see how thinking on the threat that climate change poses and the ways we could deal with it has changed over time. Obviously, the IPCC Assessment Reports provide much more comprehensive reviews of the current literature, but their emphasis is on what is new in the literature since the previous report and not on the historical dimension that we cover here.

We divide the paper into three main sections: trends, mitigation, and adaptation. Impacts of climate change are covered to some degree in the latter two sections. The literature on climate change trends is the oldest of the three areas we cover and we review some of the earliest studies that laid the groundwork for today's science and economics. The economic literature on the mitigation of climate change has its origins in the broader literature on pollution externalities and policy responses. Adaptation to climate change is a more recently emergent topic and so there is less classic literature to review.

In common with the 1992 United Nations Framework Convention on Climate Change (UNFCCC), we limit our discussion of the causes and mitigation of, and adaptation to climate change to anthropogenic 'climate change' alone. We, therefore, exclude potential causes such as variations in radiation from the sun and the earth's orbit, which are incorporated in the broader concept of climate change. Our emphasis is on change at the global level as well as differences between regions and countries rather than developments within countries. Our focus is also on impacts on the global economy rather than on the natural environment except where the latter have clear economic implications.

\section{Trends, Drivers, and Forecasts of Greenhouse Gas and Aerosol Emissions}

Understanding historical trends and forecasting future emissions are not only of scientific interest but are also needed in order to provide a baseline or 'business as usual' (BAU) scenario against which policy scenarios can be benchmarked. We focus on carbon dioxide emissions from fossil fuel combustion, as this is the most important source of greenhouse gases and the literature itself has primarily focused on these. However, we also look at deforestation and land use change, methane emissions, and sulfate aerosols. There are other economic impacts on the climate including impacts 
on the Earth's albedo from land use change and emissions of minor greenhouse gases such as nitrous oxide and CFCs and aerosols such as and black and organic carbon which we do not specifically cover.

\subsection{Effect of Emissions Growth on the Climate}

The science of the so-called greenhouse effect has its origins in the 19th century in the work of Fourier (1827) and Tyndall (1861) (Held and Soden, 2000). TyNDALL discovered that carbon dioxide and water vapor were the main greenhouse gases. Arrhenius (1896) more fully quantified the greenhouse effect and was the first to raise the issue of the effect of anthropogenic carbon emissions on the global climate. However, ArrhENIUs thought that the effects of climate change would be beneficial to society (KunNAS, 2011). CALLENDAR (1938) compared the expected warming effect from accumulated anthropogenic carbon dioxide emissions since the beginning of the $20^{\text {th }}$ century of $0.03^{\circ} \mathrm{C}$ per decade to the actual warming rate of $0.05^{\circ} \mathrm{C}$ per decade. This was the first analysis of past human-induced warming. However, in predicting future $\mathrm{CO}_{2}$ concentrations he ignored economic growth and so predicted a concentration of $396 \mathrm{ppm}$ in 2100 , a level that we have already reached. He also predicted a warming of only $0.5^{\circ} \mathrm{C}$ by 2100 , as he ignored the water vapor feedback that roughly doubles the effects of increased carbon dioxide (HELD and Soden, 2000). Several papers published by Plass in 1956 raised the alarm on climate change in a significant way for the first time. In the most cited of these, Plass (1956a) estimated that carbon dioxide concentrations would rise $30 \%$ over the 20th century and temperatures would increase by $1.1^{\circ} \mathrm{C}$, and that warming of the climate would continue for centuries if fossil fuels were extensively exploited. PLASS (1956b) presented a less technical account with a clearer warning on future warming. In it, he estimated that burning all then known fossil fuel reserves would raise global temperature by $7^{\circ} \mathrm{C}$ once a long-run equilibrium of calcium carbonate solution in the oceans was reached. Plass overestimated the direct effect of carbon dioxide, ignored the water vapor feedback and the length of time for the oceans to reach temperature equilibrium, and of course underestimated fossil fuel resources significantly. Still his estimate of the sensitivity of the climate to doubling carbon dioxide at $3.8^{\circ} \mathrm{C}$ was not much higher than today's consensus estimate of $3^{\circ} \mathrm{C}$ (KNUTTI and HEGERL, 2008).

Regular measurement of atmospheric $\mathrm{CO}_{2}$ concentrations started two years later on Mauna Loa, Hawaii following the International Geophysical Year of 1957 (KEELING, 1960). Within a few years it was obvious that concentrations were rising consistently year-by-year. KeELING et al. (1976) showed that between 1959 and 1971 the atmospheric concentration of $\mathrm{CO}_{2}$ increased by $3.4 \%$. The trend was quite smooth once a pronounced seasonal cycle was removed. Attention turned to the first long-run time series reconstruction of anthropogenic $\mathrm{CO}_{2}$ emissions from 1860 to 1969 (KEELING, 1973). KeELING's results have stood the test of time and are very close to the most recent estimates. Global emissions from fossil fuel use rose from 93 million 
tonnes of carbon content in 1860 to 3,726 million tonnes of carbon in $1969 .^{2}$ Cement production added another 74 million tonnes in 1969.

\subsection{Scenarios and Forecasts of $\mathrm{CO}_{2}$ Emissions}

The articles discussed above show that the anthropogenic climate change problem has been discussed for much longer than may be popularly assumed (BRAGANZA, 2011; Peterson et al., 2008). Economists first addressed the issue of climate change as part of the wave of interest in energy and environmental economics that followed the oil price shock in 1973-1974. The first journal article in economics on the issue appears to be D'ArGE et al. (1982), which references an earlier report (D'ARGE et al., 1975) and conference paper by the authors.

Several scenarios and projections for future emissions of carbon dioxide were published the following year (Nordhaus and Yohe, 1983; Ausubel and Nordhaus, 1983; Edmonds and Reilly, 1983a, 1983b). Edmonds and Reilly's model was the basis of the energy module of the later IS92 scenarios commissioned by the Intergovernmental Panel on Climate Change (IPCC). Many of the most important studies of future emissions have been published as reports of the IPCC and other agencies. The IPCC has commissioned emissions scenarios roughly every decade - the IS92 scenarios (LegGett et al., 1992), the SRES scenarios (NAKićENOvić et al., 2000), and the RCP scenarios (VAN VUUREN et al., 2011).

The first IPCC scenarios were produced in 1989. Due to the ending of communism in the USSR and Eastern Europe, the signing of an international agreement on the control of CFCs, and new information on various input variables, the IPCC requested a revision only two years later (LEGGETt et al., 1992). These new scenarios were inputs to the IPCC's 1992 Supplementary Report and the 1995 Second Assessment Report. These were the first scenarios to include the full suite of greenhouse gases as well as sulfur emissions (NAKIĆENOvić, 2000). In addition to the energy module described above there were deforestation, agriculture, and halocarbon emission modules. These scenarios result in a very broad range of emissions trajectories. IS92e saw emissions rising to the $20 \mathrm{Gt}$ range around 2050 and around $35 \mathrm{Gt}$ by 2100. IS92c predicted that emissions would decline after 2020. The preferred scenario, IS92a, was midway between these extremes with emissions around $20 \mathrm{Gt}$ in 2100.

The SRES scenarios prepared for the Third Assessment Report (NAKIĆENOVIĆ et al., 2000) are perhaps the best known of the IPCC scenarios. NAKiĆENOvić (2000) discusses the development of these scenarios. Four storylines were developed, which vary by population and economic growth, degree of international cooperation and trade, the rate of technological development, and the types of future policies. Five integrated assessment modeling groups cooperated to develop a total of 40 scenarios based on the storylines. For each storyline, the results from one of the modeling

2 To obtain the mass of carbon dioxide multiply by $44 / 12$. 
groups were considered the representative or 'marker' scenario of the storyline. The ensemble of results portrays greater radiative forcing than the IS92 scenarios mainly because of reduced forecasts of sulfur emissions. Since these scenarios were developed the world economy has been on a very high emissions trajectory (RAUPACH et al., 2007; GARnaut et al., 2008) following, if not exceeding, the highest SRES scenario variant A1F1.

VAN VUUREN et al. (2011) introduce the latest IPCC scenarios, known as the Representative Concentration Pathways (RCP), prepared for the Fifth Assessment Report. This process is the reverse of previous scenario-building exercises as it starts with concentration pathways based on given radiative forcing targets and then works back to socioeconomic scenarios that could lead to those outcomes. This was intended to result in better coordination across scientific disciplines (Moss et al., 2010). These pathways were supposed to be representative of the range of scenarios in the literature and are named for the level of radiative forcing in watts per square meter in 2100. The RCP 8.5 and 6.0 scenarios might be seen as business as usual under more or less optimistic assumptions about technological change while the RCP 4.5 and 2.6 scenarios assume the introduction of policies to control emissions. The RCP 2.6 scenario results in negative emissions in the second half of the 21 st century, which is only possible with biomass combustion combined with carbon capture and storage or air capture of carbon dioxide.

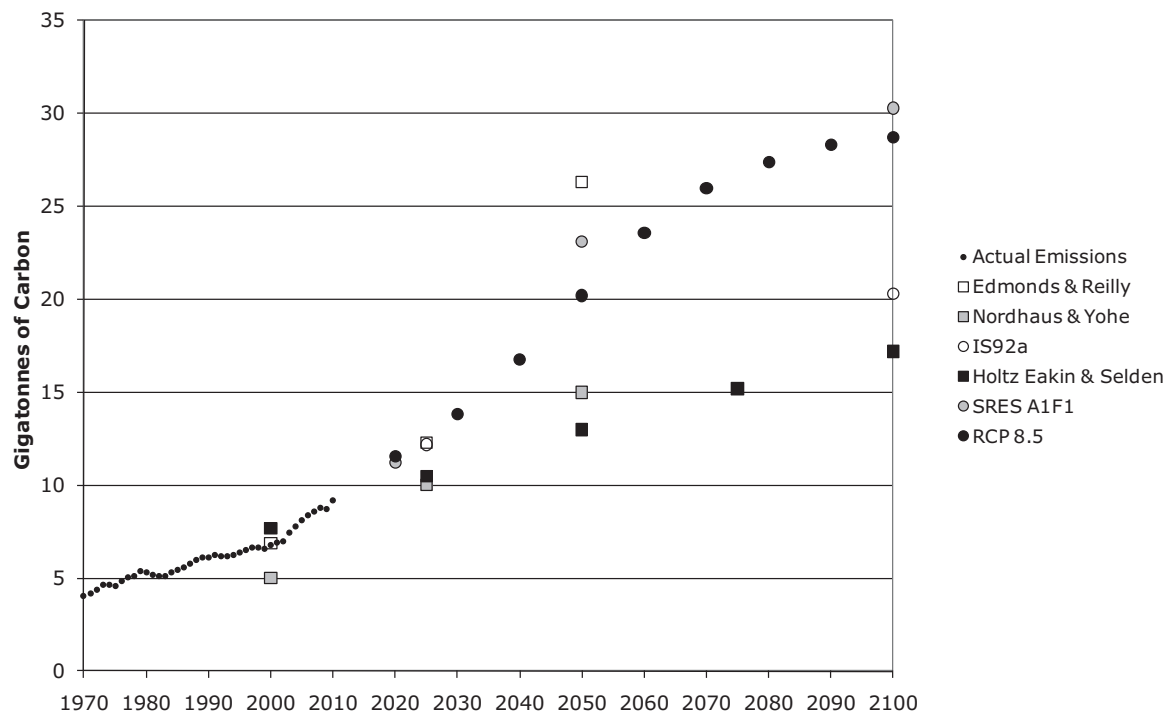

Sources: Actual emissions from fossil fuels and cement are from CDIAC. Projections from sources cited in the text.

Figure 1: Historical Projections of Carbon Emissions 
Figure 1 presents some of the key projections from the studies surveyed above and actual global emissions from 1970 to 2013. We have picked scenarios that represent business as usual and include carbon dioxide emissions from fossil fuel combustion and industry. Of the early projections that can be tested against actual realized emissions, NordHAus and YoHE's (1983) projection tracks below actual historical emissions. Edmonds and Reilly (1983b) got 2000 emissions almost exactly correct and Holtz-EAKIN and SELDEN $(1995)^{3}$ track a little above the historical number. Going forward, the selected scenarios split into low (Holtz-Eakin and SELdEN, Nordhaus and YoHe, and IS92) and high groups (EDMONDS and REILLY, SRES A1F1, and RCP 8.5). Of course, each of the IPCC commissioned studies has several other lower scenarios. We have chosen one of the higher business as usual scenarios in each case.

\subsection{Explaining Historical Emissions}

The most popular approaches to explaining historical emissions are the environmental Kuznets curve and the decomposition approach using the Kaya identity. These approaches can also be used to produce simple projections of future emissions given information on the relevant drivers.

The environmental Kuznets curve (EKC) hypothesis proposes that concentrations or per capita emissions of various pollutants rise and then fall as per capita income increases. Plassmann and Khanna (2006) and Brock and TAYlor (2010) provide static and dynamic theoretical models of the EKC respectively, while CARSON (2010) provides a recent survey. For carbon dioxide, the relevant variable is emissions per capita. Following the original paper on the topic by Grossman and KRUEGER (1991), the World Bank published an issue of the World Development Report timed for the Rio de Janeiro Earth Summit in 1992 that featured an EKC for carbon dioxide among various other environmental indicators. The econometric estimates showed that per capita carbon emissions rise monotonically with per capita income within the observed range (SHAFIK, 1994). This result was confirmed by HolTZ-EAKIN and SELDEN (1995), which is the classic paper on the carbon EKC that also found that the propensity to emit declines with income. Recent papers by WAGNER (2008), VOLLEBERGH et al. (2009), STERn (2010), and ANJum et al. (2014) that each applies new econometric methods to the problem do not substantially change these conclusions despite some intervening papers (e.g. SCHMALEnseE et al., 1998) that claimed that there was an inverted U-shaped curve for $\mathrm{CO}_{2}$ with an in-sample peak.

A related literature looks at whether per capita emissions are converging over time across countries. If there is convergence in gross domestic product (GDP) per capita, then, if the income emissions relation is monotonic, there should also be convergence in emissions, at least conditionally. STRAzicich and List (2003) examined the time paths of carbon dioxide emissions in 21 industrial countries from 1960 to 1997 to test

3 This paper is discussed below. 
for stochastic and conditional convergence. They used both panel unit root tests and cross-section regressions. Overall, they found significant evidence that $\mathrm{CO}_{2}$ emissions have converged. Subsequent research has tested whether this result holds across both developed and developing countries with mixed results depending on the method used (e.g. Aldy, 2006; Westerlund and Basher, 2008; Brock and TAylor, 2010).

A little researched topic is what happens to emissions in the short run over the course of the business cycle. Heutel (2012) and DodA (2014) report that emissions move pro-cyclically. YORK (2012) showed that emissions respond asymmetrically to increases and decreases in income with the emissions-income elasticity being greater when the economy is growing than when output is falling. Global emissions increased sharply following the 2008-9 recession in North America and Europe (PETERS et al., 2012; Jotzo et al., 2012) but it seems that this event was anomalous compared to the reaction to other recessions.

The Kaya identity is an extension of the IPAT identity (EHrLICH and Holdren, 1971) that decomposes total energy-related emissions into the product of population, income per capita, energy intensity, and the carbon intensity of energy carriers (KAYA and YoKoвori, 1997). It is important to understand that this framework is an accounting identity and not a causal model. For example, growth in income per capita might drive or be associated with reduced energy intensity so that the factors are not independent.

RAUPACH et al. (2007) is a highly cited example of this literature. They show that global emissions growth since 2000 was driven by a cessation or reversal of earlier declining trends in the energy intensity of GDP (energy/GDP) and the carbon intensity of energy (emissions/energy), coupled with continuing increases in population and per capita GDP. Nearly constant or slightly increasing trends in the carbon intensity of energy were observed in both developed and developing regions and no region was significantly decarbonizing its energy supply. The growth rate of emissions was strongest in rapidly developing economies, particularly China. This research group also published another highly cited paper in 2007 linking emissions growth and its drivers to the atmospheric concentration of carbon dioxide (CANADELL et al., 2007).

Many papers examine the role of particular Kaya factors in explaining historical emissions and driving future projections. The most important factor driving declining energy intensity, and to some degree carbon intensity, is technological change. GRÜBLER et al. (1999) present a framework for energy technology analysis and discuss methods that can be used to analyze the impact of technological changes on global warming. In the historical record, they identify characteristic 'learning rates' for reductions in the cost of energy technologies that allow simple quantification of the improvement in cost and performance due to cumulative experience and investments. They also identify patterns, processes, and timescales that typify the diffusion of new technologies in competitive markets. Technologies that are long-lived and are components of interlocking networks typically require the longest time to diffuse and coevolve with other technologies in the network. Such network effects result in high 
barriers to entry even for superior competitors. The authors show how it is possible to include learning phenomena in micro- and macro-scale models. Doing so can yield projections with lessened environmental impacts that do not necessarily incur a negative penalty on economic activity.

The authors also investigate the final Kaya factor - carbon intensity of energy. They show that, over time, the fuels that power the economy have had progressively more energy per unit of carbon pollution. Such replacement has historically 'decarbonized' the global primary energy supply by $0.3 \%$ per year.

Besides technological change, another potential driver of declining energy intensity is structural change of the economy towards a service-oriented economy. It is usually thought that such an economy will have lower energy intensity and, therefore, emissions intensity of income. HenriQues and KANDER (2010) argue that this interpretation is overly optimistic because the shift to a service economy is somewhat of an illusion in terms of real production. The share of an industry in the economy is a function of both the real level of production and the price of output. The share of the manufacturing sector has declined in developed countries because rapid productivity gains have reduced its output price relative to the service sector. When constant prices are used, less of a shift to a service economy is seen. The main driver of the decline in energy intensity in developed countries is, therefore, productivity gains in manufacturing. For emerging economies like Brazil, Mexico, and India, it is the residential sector that drives energy intensity down because of the declining share of this sector in energy use as the formal economy grows and there is a switch to more efficient fuels in the household.

Another important issue in the decomposition literature is to what degree trade and foreign investment have allowed developed countries to reduce their apparent energy intensity. Since the early days of the environmental Kuznets curve literature, this was seen as a potential explanation of reduced pollution in developed economies (STERN et al., 1996). Most mainstream economists (LEVINSON, 2010) and economic historians (e. g. KANDER and LindMARK, 2006) have argued that the role of trade in reducing energy and emissions intensity is small. Peters and Hertwich (2008), however, find that most developed countries were net importers of embodied carbon dioxide emissions in 2001 - in other words, their imports required more emissions to produce than their exports did. For the United States, the difference amounted to $120 \mathrm{Mt} \mathrm{C}$ while for the UK the difference was $28 \mathrm{Mt}$. But this does not imply that if these countries produced all these products domestically that their net emissions would be this much higher. This is because production in developing countries is much more energy intensive than in developed countries when measured at market exchange rates, and some developed countries, in particular China and India, are particularly carbon intensive (KANDER et al., 2015).

\subsection{Emissions Other than Carbon Dioxide from Fossil Fuels}

Deforestation and land-use change are important sources of emissions of $\mathrm{CO}_{2}$. Total emissions are much lower than emissions from energy related sources but much more 
uncertain. Houghton (2003) presents estimates of $\mathrm{CO}_{2}$ emissions from land-use change from 1850 to 2000, globally and by region. In general, the level of annual emissions rose from 1 to $2 \mathrm{Gt} \mathrm{C}$ over the 150 years with an acceleration in the trend around 1950 in common with emissions from energy-related sources. Therefore, there is a clear link with economic growth. Tropical deforestation, particularly in Asia and Latin America, is the dominant source of emissions. In recent decades there has been net reforestation in developed countries. The data are increasingly uncertain in recent decades with estimates from different researchers varying substantially (HougHTON, 2010).

The third most important greenhouse gas in the atmosphere, and the second most important in terms of anthropogenic emissions, is methane. In comparison to $\mathrm{CO}_{2}$, relatively little work has been done on $\mathrm{CH}_{4}$. STERN and KAUFMANN (1996) used available data to reconstruct the first time series of historic emissions from 1860 to 1993. They found that anthropogenic emissions had increased from 80 million tonnes of carbon in 1860 to 380 million in 1990 . The relative importance of the various emissions sources changed over time, though rice farming and livestock husbandry remained the two most important sources.

Offsetting the radiative forcing due to greenhouse gases is a significant negative forcing due to aerosols derived from sulfur oxide (primarily dioxide) emissions. These aerosols do not persist in the atmosphere for usually more than a few days and so the source of emissions is important and effects are localized despite the spread of pollution across borders to neighboring countries. The main sources of anthropogenic sulfur emissions are coal combustion and metal smelting. STERn (2006) showed that after increasing fairly steadily from 1850 to the early 1990s global emissions began to trend downwards. Emissions in Western Europe and North America as well as Japan had already been trending down since 1970 primarily due to policies to reduce acid rain (STERN, 2005). But this decline was offset by growth in other regions. After 1990, there was a dramatic reduction in emissions from Eastern Europe and the former Soviet Union. It is likely that these emissions will continue to decline in the future, contributing to future warming. Whereas STERN (2006) used a combination of previously published data and model estimates, SMITH et al. (2011) provide an inventory of sulfur emissions from 1850 to 2005 using a uniform methodology. The results largely confirm STERN's (2006) findings though the levels are generally a few percent lower.

\section{Mitigation of Climate Change}

As shown in the first part of this paper, effective global mitigation would require reversing the historical trend in greenhouse gas emissions. This is likely to result in significant net economic costs. The benefits from reduced future climate change need to be balanced with the costs of mitigation, which is one of the core areas of economic analysis on climate change. 
Climate change has been described as 'the biggest externality the world has ever seen' (STERN, 2007) because the negative impacts from any person's or firm's greenhouse gas emissions are spread across the globe and over a long period of time. These externalities create coordination problems between countries because from the perspective of a nation state there are strong incentives for freeriding on other nations' mitigation efforts (BARRETT, 1990). There are also important questions about how the global mitigation effort should be distributed between nations ('burden sharing' or 'effort sharing'), and how reductions in emissions can be reconciled with economic development especially in the poorer nations.

To minimize the costs of achieving a given mitigation outcome, cost-effective policies are needed. The economic approach is to give incentives to businesses and individuals to change their choices in production and consumption; the regulatory approach is to prescribe or forbid particular processes, products, and activities.

\subsection{Estimating Costs and Benefits: How Much Mitigation is Optimal?}

There is scientific consensus that reducing greenhouse gas emissions is necessary in order to reduce future climate change impacts and to limit the risk of extreme climate change impacts. The global consensus on climate change action is reflected in the 1992 UN Framework Convention on Climate Change, which states that 'the ultimate objective of the Convention is to achieve stabilization of greenhouse gas concentrations in the atmosphere at a level that would prevent dangerous anthropogenic interference with the climate system' (Article 2).

But what degree of climate change is 'dangerous'? How much effort should societies make in mitigating climate change when this means allocating scarce resources away from other goals? In economics this question is usually approached as a form of cost-benefit analysis. In evaluating a particular climate change mitigation scenario, the costs of reducing emissions are compared to the benefits that arise through reduced damage from climate change impacts. The theoretical condition for optimal mitigation is that the marginal cost of abatement is equal to its marginal benefits. In other words, the cost of reducing the last tonne of emissions should be equal to the marginal damages from those emissions, or the value of the last unit of climate change damages avoided.

The majority of economic analyses of climate change mitigation only look at the economic costs of policies to reduce emissions, not the economic effects of the resulting differences in climate change impacts. A classic reference is WEyant (1993). The academic literature contains thousands of applications using different modeling approaches - most frequently computable general equilibrium models, but also partial equilibrium models and engineering type models, as well as macroeconomic models - and applications to different scenarios, regions, and economic sectors.

Most of the literature on the costs of climate change mitigation also focuses only on the costs of moving to lower-emissions technologies and practices, not on the potential co-benefits of mitigation action that may occur, in addition to fewer da- 
mages from climate change. An example is the reduction in air pollution that goes hand in hand with reduced or more efficient use of fossil fuels, and which could yield large economic co-benefits (GroOSMAN et al., 2011).

However, there is also a large literature that addresses the more complex empirical question of the optimal amount of mitigation, and the social cost of carbon emissions. The classic global model of optimal mitigation is William Nordhaus' DICE and RICE models (Nordhaus, 1993; Nordhaus and Yang, 1996). This and other models that take the same fundamental approach - for example the PAGE (HopE et al., 1993) and FUND models (ToL, 1997) as well as more recent models such as the WITCH model (Bosello et al., 2010) - are referred to as 'integrated assessment models' because they model simultaneously the costs of climate change impacts and the costs of climate change mitigation.

These models yield estimates for the social cost of carbon and, thus, the optimal marginal cost of emissions reductions. Meta-analysis of such studies (ToL, 2002) shows a wide range of empirical estimates, due to uncertainty about future economic and environmental parameters, different assumptions about economic relationships, and different methods of evaluation.

Economic models are by necessity limited in the extent to which they can incorporate detailed and reliable cost estimates. This is true in particular for future climate change damages, which tend to be much more uncertain than estimates of mitigation costs. For example, most economic integrated assessment models use simple aggregate damage functions that translate temperature increases to changes in economic output. These limitations are generally acknowledged by the creators and users of integrated assessment models and have been highlighted in the critical literature (ACKERMAN et al., 2009). Nevertheless, there is a tendency in applied policy assessment exercises to take the results of applications of the models quite literally; ignoring their limitations and relying on assumption-driven model output. Questions remain in particular about the validity of the damage functions used in integrated assessment models (PINDYCK, 2013).

A key limitation of assessments of the benefits of climate change mitigation are that typical economic analyses include only the impacts from climate change that are reflected in markets, for example lower agricultural yields, greater costs for infrastructure maintenance, reduced labor supply due to illness, and so forth. Even these may not be completely covered, because some of the likely future market impacts are difficult to quantify. Non-market impacts may include the loss of ecological functions, reduction in quality of life, and loss of cultural values (GARNAUT, 2008). Economic analysis sometimes attempts to proxy these costs but the valuations necessarily remain subjective.

A second important limitation is that climate change impacts are uncertain. Future physical impacts from climate change are subject to significant uncertainty, and this is compounded by uncertainty about how physical impacts will translate into economic effects. Some economic modeling exercises attempt to capture this uncertainty by doing a stochastic analysis of impact scenarios and reporting results as averages over 
many different model runs. This approach was adopted for example by the Stern Review (STERN, 2007), an influential report on the economics of climate change mitigation produced for the UK government (see also STERN, 2008).

But even so, the question remains whether and to what extent special weight should be given to the possibility of extreme or 'catastrophic' climate change outcomes. As WeITZMAn (2009) shows, if the probability distribution of climate change impacts has a 'fat tail', where the probability of extremely high damages does not quickly tend to zero and there is a non-zero risk of the wipe out of all economic activity, then a theoretically optimal strategy may mean devoting all of society's economic resources to climate change mitigation. To most analysts this is self-evidently not the correct prescription. It shows the limits of the economic analysis of the costs and benefits of mitigation.

A third key point is the importance of the discount rate applied to climate change damages and mitigation costs. The extent to which costs and benefits that occur decades or centuries into the future are valued today can be the decisive parameter choice in the empirical analysis of optimal mitigation and the social cost of carbon. A fundamental question is whether climate change analysis should follow a positive approach and use discount rates calibrated to observed interest rates in markets, or a normative approach (GOULDER and WiLliams, 2012).

A commonly used approach is to follow the RAMSEY (1928) rule, where the dollar discount rate is the sum of the pure rate of time preference and the rate at which future generations' income should be discounted in order to account for the fact that they are expected to be richer than people today. The latter is a multiple of the elasticity of the marginal utility of consumption and the future rate of economic growth. STERN (2008) made the case for a near-zero pure rate of time preference in climate change analysis, and today this is a widely accepted normative assumption (GoLLIER, 2012). However, there is ongoing debate about the relevant parameter range for the elasticity of the marginal utility of consumption (QuigGIN, 2008). The social discount rate also relies on assumptions about the future growth in per capita income. Thus a wide range of different social discount rates can be justified, and they lead to different conclusions about the optimal extent of global mitigation.

Economic welfare analysis of climate change policy is further beset by the necessity to aggregate individual welfare into a collective welfare function, putting a value on lives lost and many other issues that require normative judgments. As a result, the question of how much the world should mitigate greenhouse gas emissions is not just one of economic analysis, but fundamentally one of ethics and values.

\subsection{Equity: Who Should Pay for Mitigation?}

Inherent in climate change and mitigation are fundamental inequities. The climate change impacts experienced and the associated costs and benefits will differ greatly across individuals, groups in society, and nations. The opportunities to reduce emissions and the costs of achieving a given reduction vary across countries, as does their 
economic capacity to pay for these costs. The annual contribution to global greenhouse gas emissions also varies greatly among countries on a per capita basis, and accumulated emissions over time vary even more.

A large literature on 'burden sharing' or 'effort sharing' examines different models for distributing the effort and cost of mitigation action between the world's nations. A central tenet in trying to resolve conflicting views over who should pay for mitigation is the question of equity and the quest for fairness in allocating the global mitigation burden (GRUBB, 1995). It can be argued that because effective mitigation requires the voluntary collaboration of many sovereign nations, the distribution of costs and benefits needs to be acceptable to individual nations. Of course, notions of what is fair differ among both individuals and nations and will often be influenced by self-interest (LANGE et al., 2010).

Developing countries occupy a special place in discussions of equity and effectiveness of global mitigation. The rising share of developing and industrialized countries in global emissions means that they will need to be fully engaged in mitigation for any effective global results. On the other hand, poorer countries have strong arguments on equity grounds that they should be free to catch up in their economic development, and/or that richer countries should pay for the cost of some or all of the mitigation action undertaken in poorer countries.

As shown in the first section, it is not possible to reduce global emissions if developing countries follow a similar pattern of emissions intensive growth as the industrialized nations have. Therefore, a pressing question is how development objectives can be best met in tandem with mitigation. The climate change issue and how it relates to development is part of the broader question of sustainable development (BEG et al., 2002), more recently termed 'green growth'.

\subsection{Policy Frameworks: How Can We Achieve Mitigation Cost-Effectively?}

Economic modeling of mitigation usually assumes that emissions reductions are made in the most cost-effective manner, usually represented by a uniform price signal on emissions, through an emissions tax or an emissions trading scheme. The largest such actual price-based scheme is the European emissions trading scheme (ELLERMAN and BUCHNER, 2007).

In reality, many other types of economic and regulatory policies are being used for mitigation, which differ in their stringency and marginal costs and have overlaps and interactions. Overlapping policies will usually increase the economic costs relative to the first-best outcome (SORRELL and SiJM, 2003). On the other hand, existing market failures will require specific interventions that go beyond uniform pricing of emissions. A prominent example is innovation of lower carbon technologies, where knowledge externalities can result in suboptimal private investment even in the presence of emissions pricing (JAFFE et al., 2005). Social rates of return on research and development are usually higher than private rates of return (GRILICHES, 1992). Different policy instruments may also serve policy objectives that are distinct from but con- 
nected with mitigation, for example support for renewable energy technologies with the objective of giving new industries a competitive advantage or improving domestic energy security (BoYd, 2012; KENNEDY, 2013).

A further constraint on the efficacy and cost effectiveness of economic policies for mitigation is the credibility of the interventions. Many mitigation options rest in investments in physical assets with long lifespans. Thus investment decisions will be influenced more by expectations about future policy settings than present policy settings (UlPH and ULPH, 2013). To be effective, mitigation policies need to be credible and their stability assured in the face of political change. Designing such policy frameworks includes creating constituencies for the retention of policies over time. An example of economic thinking that aims for such policy sustainability is the MCKIBBIN and WILCOXEN (2002) proposal, which would allocate long-term emissions permits to individuals in the hope that this would create a lobby for the retention and, possibly, strengthening of carbon emissions constraints.

Policy models that could perform well in theory often are not feasible in practice because of institutional and political constraints. A large body of applied literature investigates alternative international mitigation policy frameworks (e.g. Aldy and STAVINS, 2007).

In the end, both qualitative and policy oriented research, as well as more stylized formal analysis (WoOD, 2011), put the spotlight once more on the difficulty of achieving cooperation between nations. Coupled with a tendency to put a relatively low weight on uncertain future climate change impacts relative to pressing immediate economic concerns, this can yield a negative assessment of the prospects for strong global climate change mitigation.

The less climate change mitigation action is undertaken, the greater the need for societies to adapt to impacts from climate change, and the more important the role for economic approaches to adaptation policy. This is the subject of the third part of the paper.

\section{Impacts and Adaptation to Climate Change}

Adaptation to the impacts of climate change was generally regarded in the $1980 \mathrm{~s}$ as a policy complement to the reduction (mitigation) of greenhouse gas emissions, but was subsequently generally ignored by the scientific community until the past decade or so. Tol (2005) drew attention to the political incorrectness of adaptation 'because it presumably implies accepting defeat in the battle against evil emissions', and PIELKE et al. (2007) agreed that the topic of adaptation was something of a taboo for a long time. It is an open question whether the resulting bias in research effort will be disproportionately detrimental, especially in countries that are less able to respond to a changing climate.

It is true that the Intergovernmental Panel on Climate Change (IPCC) included adaptation in each of its Assessment Reports, but treatment was relatively cursory 
when compared with mitigation and the projected impacts of climate change. As KATES (1997) noted, the second volume of the 1995 IPCC Second Assessment Report devoted only 32 pages (less than 4\%), spread over 18 chapters, to adaptation. He attributed this to the existence of two contending schools of thought: 'preventionists', who considered that adaptation might weaken societies' willingness to reduce greenhouse gas emissions, and 'adaptationists', who argued that little adaptive action was required because climate change would occur slowly enough for nature and humankind to adjust normally. KLEIN and MACIVER (1999) further note that it took the IPCC ten years to organize a workshop on adaptation to climate change, first held in Costa Rica in 1998.

It may still be the case that climate change scientists are generally less willing to countenance the possibility of adaptation. In an article on adaptation to climate change in a scenario of $4^{\circ} \mathrm{C}$ global warming, for example, VINCE $(2009$, p. 29) reports that:

'If this [ $4^{\circ} \mathrm{C}$ global warming by 2050 ] happens, the ramifications are so terrifying that many scientists contacted for this article preferred not to contemplate them, saying only that we should concentrate on reducing emissions to a level where such a rise is known only in nightmares.'

\subsection{Defining and Framing Adaptation}

In an important sense, adaptation to climate change presents a more complex policy problem than mitigation. Mitigation can be approached as a single, easily defined goal, akin to a cost-effectiveness analysis. Adaptation, on the other hand, has many facets, precluding not only simple answers, but also simple approaches.

A particular problem in analyzing adaptation to climate change is the varied effects and impacts that climate change will have and the ways these impacts will affect different activities and be experienced by individuals (BERKHOUt, 2005). ScherAgA and GRAMBSCH (1998) highlighted the difficulty of generalizing. The spatial impacts of climate change are likely to differ: although average global temperatures may have risen to date, some parts of North America have experienced falls, with increases in others. Different demographic groups will similarly experience the effects of climate change differently and adapt to them in different ways. Even a single effect may simultaneously generate costs and benefits: increased water temperatures may reduce the viable habitat of cool water fish like trout, but increase that of other fish sought for recreational fishing. Implementation of adaptation measures may yield benefits but it also comes at a cost: both must be assessed in considering various trade-offs, including residual impacts. Different climate change effects may occur simultaneously, so their effects on complex systems cannot be considered independently. For example, the establishment of fish hatcheries to replenish stocks reduced by climate change may alter biodiversity in fishing grounds, reduce genetic diversity, or facilitate transmission of diseases and parasites. 
The possibility that climate change can have differential effects within society reinforces the need for detailed study of particular systems, rather than precipitate implementation of apparently obvious universal solutions. A pertinent example is a study by LuDwiG et al. (2009), who modeled the effect of a large decline in rainfall on a number of sites in the Western Australian wheatbelt. Simulations indicated that not only did crop yields not fall, but leaching of fertilizer also decreased, thus reducing costs to farmers, and the spread of dryland salinity was reduced significantly. Further, beneficial profit outcomes were obtained through minor variations in planting periods for two wheat varieties. Because of this diversity, sectoral studies, often at a localized or regional level, are common. Agriculture in particular is a field well traversed (e.g. Laube et al., 2012; Liu et al., 2008; Howden et al., 2007; Chen and ZonG, 1999; ERDA, 1996; TrI et al., 1998), with some attention devoted to the health sector (e.g. Kovats and Akhtar, 2008; McMichael et al., 2006; Kinney et al., 2008; PATZ et al., 2005) and coastal protection (e. g. ZHU et al., 2007). Economic analyses of adaptation in the secondary and tertiary sectors are rarer. Possibly reflecting the techno-scientific approach of the IPCC, studies of consumer preferences for adaptation priorities and willingness to pay as an indication of benefits to be achieved are virtually absent.

Social perceptions of the effects of climate change will inevitably change over time and will, therefore, affect concepts of requisite or desirable adaptation. For example, the Summer 2003 heat wave in Europe is considered to have caused significantly more deaths among the elderly than normal, and understandably led to considerable public concern. However, one might also envisage a situation where habituation over a longer period could result in heat-related deaths among the elderly being regarded as a 'normal' aspect of European summers (OPPENHEIMER, 2005). Alternatively, gradual acclimatization may reduce heat-related mortality. It is, therefore, necessary to recognize that adaptation can change in form and nature over time.

Adaptation should not necessarily mean implementation of 'climate proofing' measures that are intended to totally offset the biophysical effects of climate change. For example, installation of air conditioning in all buildings and vehicles in a city may be feasible, but would be costly. In practice, residents may be willing to internalize some of the effect of higher temperatures in order to contain costs or taxes.

Implementation of adaptation measures can also result in so-called maladaptation (MENDELSOHN, 2000); a situation where the additional social cost of the measure exceeds any extra social benefit. BARNETT and O'NeILL (2010) posit five types of maladaptation, including concomitant increases of greenhouse gas emissions, shifting of costs to the poor, and reductions in incentives to adapt. In their study of flood responses in Norway, NAESS et al. (2005) report that local government construction of dykes under pressure from vested interests to fix short-term problems resulted in damage to fish spawning grounds as well as removal of vegetation favored by birds.

Just as cost-benefit analysis requires specification of 'standing' (the perspective from which analysis is to be conducted), adaptation policy requires clarity about risk, scale, values, and governance. The specific interest (values) of someone whose sea- 
side house is about to fall into the sea is to press for construction of a sea wall or regular sand replenishment along the beach, but government coastal authorities may have broader environmental or social interests that do not encompass saving an individual house (ADGER et al., 2009). URWIN and JORDAN (2008) express a similar sentiment in writing that analysis of bottom-up perspectives on policy implementation shows 'how divorced much activity at the street level' is from formal top-down approaches.

Strategic, 'planned' adaptation implemented by techno-scientific experts and government agencies on the basis of their expectations of climatic impacts can be contrasted with 'autonomous' adaptation by individuals acting in their own self-interest by adjusting to changes in local conditions. KLEIN and MACIVER (1999) portray such autonomous adaptation as being reactive by definition, while planned adaptation can be both reactive and pro-active.

There are large uncertainties involved in predicting both the overall extent of future climate change and the frequencies and severity of extreme events, as well as the socioeconomic conditions that will determine their impacts (MEARNS et al., 2001: 756; Visser et al., 2000; Jones, 2000; Giorgi, 2005). Though the IPCC (2012) has provided detailed assessment of the uncertainties associated with various climate impacts, CURRY (2011: 730) argues that the IPCC's consensus approach is biased because it excludes contrary views.

KATZ and BROWN (1992) highlight a further uncertainty in predictions of climate impacts relevant to adaptation. While global climate models focus on averages, the impacts on society will be felt primarily through extreme events. KATZ and BROWN (1992) and others (e.g. Wigley, 2009; Cooley, 2009; Hunter, 2010) recommend the use of extreme value distributions to better estimate likely effects. WEITZMAN (2009) considers the structural uncertainty contained in the 'fat tails' of extreme value distributions to be even more important than the debate about discount rates in assessing the costs and benefits of climate change. But in an iterative Delphi survey of environmental economists on adaptation to climate change Doria et al. (2009: 818) found that there was no agreement on whether a 'risk-based approach [was] more appropriate than [a] welfare economic or vulnerability framework', or whether mitigation should be included in any definition of adaptation.

Over the last two centuries, governments across the globe have increasingly adopted the role of managers of the risks faced by their citizens. Limited liability for entrepreneurs and shareholders was followed by, among others, workers' compensation, unemployment benefits and other social services, disaster relief, consumer protection legislation, health and disaster insurance, environmental protection, and mitigation of greenhouse gas emissions (Moss, 2002). There seems little reason to believe that governments will not seek to extend their role into issues related to adaptation to climate change. The key question is: how can they best go about it?

Governments at all levels face a fundamental dilemma. Premature or unnecessarily excessive adaptation today will involve immediate costs, while any benefits gained may not be reaped until the future, possibly the distant future. On the other hand, 
undue procrastination or inadequate measures may result in property damage or even loss of life. Care is required, however, in attributing increased losses to climate change itself. For example, Pielke and Landsea (1998) and Crompton and McANENEY (2008) show that there has been little or no discernible trend in the frequency of hurricanes and other meteorological hazards once damage values have been normalized for inflation, wealth, and coastal populations.

Maladaptation can further increase costs at the risk of gaining no benefit or even worsening the situation. MendelsoHn $(2000 ; 2006)$ argues that individuals and markets in traded sectors such as agriculture will adapt efficiently, unless governments intervene inappropriately through policies such as subsidizing water or insurance, which encourage the continuation of risky behavior rather than efficient adaptation. Government support is, however, required for public goods such as biodiversity. Where impacts involve both markets and public investment, such as water, coastal defenses, or heat stress, a combination of markets and government intervention is required to ensure efficient outcomes. FANKHAUSER et al. (1999) add that research funding and the removal of legal, social, and political constraints are also valid functions of government.

\subsection{Decision Making Aids}

Recognizing that the natural and social sciences have different implicit and explicit conceptual understandings of 'adaptation', SMIT and WANDEL (2006) identify four broad analytical approaches that have been adopted by researchers:

- composite indices;

- statistical, equilibrium, and scenario modeling;

- cost-benefit, cost-effectiveness and multi-criteria analysis;

- 'bottom up' studies at the local level.

\subsubsection{Indices of Vulnerability, Adaptive Capacity, and Resilience}

Much of the academic literature has focused on exploring concepts such as the 'vulnerability' of a particular area or community, 'adaptive capacity' in that location, and hence its overall 'resilience' to climate change impacts. Extensive reviews and categorizations of the literature can be found in FuESSEL and KLEIN (2006), JANSSEN et al. (2006), and MiLler et al. (2010). But analyses based on these concepts provide little practical guidance for operationalizing adaptation strategies, particularly in terms of the timing of implementation or its optimal level.

Some analysts have promoted composite indices that aggregate weighted scores for aspects of the 'vulnerability' of particular areas (e.g. PERCH-Nielsen, 2010; Hahn etal., 2009; Sullivan and Meigh, 2005; Harmeling and Eckstein, 2012). While vulnerability indices at one level are just descriptive summaries, there is an inevitable tendency to treat them as decision-making tools, with implicit or explicit assumptions that, for example, the most vulnerable areas should have the greatest 
claim on adaptation funds. Fuessel (2009b: 8) concludes that indices of vulnerability 'show substantial conceptual, methodological and empirical weaknesses'. Cox (2009) further points out that impacts that are chosen for inclusion in indices may not accord with the essential condition of additive independence if the impacts are interactive. Where risks are correlated, additive indexes 'can perform even worse than setting priorities randomly' (Cox, 2009: 942), with obvious implications for setting funding priorities. Pollitt (2010) is also less than enthusiastic about the use of composite indicators and indices to reduce multifaceted, complex, and sometimes countervailing issues and criteria to single numbers. VINCENT (2007) points out that composite indices cannot be scaled from specific local data to globally comparable indicators.

\subsubsection{Modeling Scenarios}

Scenario analysis is considered by some to be 'a tool for decision-making under uncertainty' (e. g. Schwartz, 1991; Economics of Climate Adaptation Working Group, 2009: 37). While scenarios may provide a useful framework for thinking through possible impacts and potential responses, this approach leaves the problem of uncertainty unresolved. For example, choice of the common "low, medium, high" scenario approach still leaves the decision-maker with the problem of guessing which level is the most likely. The greater the number of scenarios, the more indeterminate will be the choice.

Much of the early adaptation literature flowed from the focus of the IPCC on identifying and specifying the impacts of climate change scenarios. BURTON et al. (2002) offer a number of reasons why 'models and climate scenario-based methods have not yielded useful results for the purposes of adaptation response and policy options'. Climate scenarios are generally global or regional, while adaptation needs to be sitespecific and is determined by extreme climatic events rather than the average values produced by climate models. Scenarios themselves only offer a range of possibilities in diverse fields (health, education, energy, ecosystems, etc.), thus compounding the uncertainties of modeling climate impacts: decision-makers have no concrete basis for making decisions. Further, impact analysis is not designed to assess alternative adaptation measures such as reducing perverse incentives in long-term drought support. Universal, 'obvious' adaptive responses also ignore the realities of local institutions, culture, and potential barriers to change. Human societies have always adapted to changes in climatic environments, so that adaptation policy should be considered more holistically, for example in the context of broader agricultural policy. MERCER (2010) takes a similar position in terms of considering climate change within the context of development policy.

Statistical and equilibrium models have been used to estimate the net costs of climate impacts with and without adaptation (e.g. Mendelsohn et al., 2000; ToL, 2002). Such broad scale studies tend to accept that some form of assumed or hypothetical adaptation will automatically occur, and that its marginal cost is equal to the marginal benefit of avoiding the impact. HANEMANN (2000) critiques aspects of 
impact models, pointing out that adaptation may involve changes in preferences (habituation or hedonic adaptation) as well as in behavior. In commenting on the Ricardian approach pioneered by MENDELSOHN et al. (1994, 2000) to assess global market impacts of climate change on agriculture and other sectors, HANEMANN (2000) contrasts it with agronomic models that estimate the impact of climate change on crop yields to predict the economic effect on agriculture. In contrast, the Ricardian approach uses cross-sectional data from different locations to estimate the effect on land values of changes in climate variables such as temperature or rainfall, while controlling for soil types and other geographic and socioeconomic factors. Different scenarios are then used to assess the impact of climate change on the value of farmland and, by inference, on agricultural productivity. Although HanEMANN's (2000) focus is on errors in estimation of the agronomic and Ricardian approaches, he notes that the latter assumes that all farmers have identical choice sets in terms of crops to plant, costs, etc. More recent work by Kurukulasuriya and Mendelsohn (2008) seeks to integrate the agronomic and Ricardian approaches by allowing for switching of output choices by African farmers, using a multinomial logit model while distinguishing different agro-ecological zones. The intricacies and limitations of various modeling approaches are reviewed by DARwin and Tol (2001), Hitz and SMITH (2004), and Callaway (2004).

Geographic (spatial) and historical (temporal) analogues can also inform decisionmakers about the likely impacts of different climates and therefore suggest possible adaptation strategies. HALLEGATte et al. (2007) simulate climate scenarios with two climate models and identify 'reasonable analogues of the future climates of 17 European cities' in terms of temperature and rainfall and the costs of adaptation to the state of analogue cities. For example, Paris can be expected to be either Bordeaux-like or Cordoba-like in the future, requiring more thermal insulation and air conditioning for buildings, reduced density, and more vegetation for shade, etc. MENDELSOHN et al. (1994) also use spatial comparisons in modeling of impacts on agriculture from a Ricardian perspective. In another example, VAN DER ENG (2010) uses the effect of drought on rice farmers in Java in the 1930s as a model of the adaptability of rice markets in potentially similar climatic conditions in the future. ORLOVE (2005) draws on cases such as the abandonment of Viking settlements in Greenland as analogues. ToL et al. (1998) review a number of other studies that employed temporal and spatial analogues to gauge the nature and extent of adaptation that may be required in the future.

\subsubsection{Cost-Effectiveness, Multi-Criteria Analysis and Cost-Benefit Analysis}

Cost-effectiveness analysis is often used in everyday life, and it is easily presented to, and understood by policy makers. A measure of technical efficiency, it expresses a result in terms of the cost of achieving a specific objective, for example the number of lives saved for the cost of a dyke. At its most simple, it can reveal projects that generate the 'biggest bang for the buck'. Although generally used only for a single output or effect, cost-effectiveness analysis can be extended to multiple outputs and 
inputs through data envelopment analysis or stochastic frontier analysis and related techniques. However, the very lack of a common variable or numeraire to represent 'adaptation' means that comparisons can be made only between projects of a very similar nature. It is not possible to compare a dyke project with a water project, for example, if the comparison made is between number of lives saved per dollar and kilograms of additional rice grown per dollar. Cost-effectiveness analysis also cannot be used to assess which projects will generate the largest benefits for society as a whole. It is, therefore, of only limited use as a policy decision tool for comparing different adaptation projects and programs.

Multi-criteria analysis is a seductively simple approach to developing policy recommendations. Unlike cost-benefit analysis, however, it lacks an established theoretical basis and is inevitably subjective in the choice of impact attributes, weights, and scores. Multiple results are possible for any given study because their focus is generally 'single-issue', compared to evaluating the effect of a measure on society as a whole. Multi-criteria analysis, essentially a form of composite index, involves the aggregation of incommensurable quantities and therefore breaches the mathematical principle of dimensionality (DoBES and BENNETT, 2009).

DE BRUIN et al. (2009) provide an example of the application of multi-criteria analysis to identify and rank adaptation priorities in the Netherlands. Their study considers 96 specific adaptation measures for seven climate-sensitive sectors in the Netherlands. Although he suggests further work in the area, Fuessel (2009a) notes the subjective nature of the criteria used, a systematic bias in favor of comprehensive policy options, and vague definitions. DE BRUIN et al. (2009) themselves acknowledge that two out of their five scoring criteria are not mutually exclusive and may, therefore, involve double counting.

Some authors (e. g. Agrawala and Fankhauser, 2008: Table 1.1) assess adaptation measures in terms of so-called 'cost-benefit' analysis. However, such approaches are more accurately characterized as 'cost-cost' studies, because they compare the cost of implementing an adaptation measure with the cost of avoided damage due to climate change effects. While there is sometimes no alternative to using the 'damage costs avoided' approach, it can only provide a rough proxy for benefits in terms of willingness to pay or willingness to accept. For example, flood damage to a household will generally underestimate economic costs because it will not include the value of destroyed photographs or other family memorabilia. Valuing the destruction of crops, on the other hand, may overestimate damage costs because farmers may adapt in future by planting alternative crops or by substituting capital in the form of irrigation drip systems. At the international level, estimating the likely costs of the impact of future climate change is a popular line of inquiry, probably because it provides a negotiating basis for requesting financial assistance. However, the estimation of damage costs alone provides little policy basis for determining the socially desirable extent or nature of adaptation activity. In this respect, DiETz and MADDISON (2009: 303) note that surprisingly little is known "about people's preferences for a particular climate or their willingness to pay to avoid negative impacts of climate change". 


\subsubsection{Bottom-Up Studies}

Generally prevalent in the grey literature, 'bottom up' studies seek to describe practical adaptation measures at local levels on the basis of community experience (e.g. JABEEN et al., 2010). They tend to support 'mainstreaming' of adaptation measures within established systems and processes. Their findings are generally limited to local conditions and circumstances, but may nevertheless provide useful lessons for communities in climatically analogous situations.

\subsection{Decision-Making Approaches and Instruments}

\subsubsection{Uncertainty and 'Real Options'}

One approach to dealing with the inherent uncertainty of climate change is the use of 'real options' to extend conventional cost-benefit analysis by estimating quasi-option values using techniques originally developed for financial options by BLACK and SCHOLES (1973). In essence, real options analysis posits that additional value is gained from flexibility in the face of uncertainty about future costs and benefits if it is possible to delay or partially delay a decision to fully implement a decision until better information becomes available. DiXIT and PINDyck (1994), Trigeorgis (1997), Luerhman (1998), Amram and Kulatilaka (1999), and Copeland and ANTIKAROv (2001) all adopt different approaches to estimating the value of real options. BORISON (2005) finds that the different approaches can produce contradictory results, depending on assumptions made. Real options have been applied to adaptation-type issues by Michelsen and Young (1993), NordviK and Liso (2004), Hertzler (2007), Dobes (2010), Leroux and Crase (2010), McClintock (2010), IBRD (2010), Dobes (2012), Linquiti and Vonortas (2012), MAYBeE et al. (2012), and Gersonius et al. (2013).

LiNQUITI and VonORTAS (2012) compare five strategies that boundedly rational planners or decision-makers might employ to protect Dhaka and Dar es Salaam by constructing sea walls from uncertain levels, frequency, and timing of inundation. They use stochastic simulation modeling employing a Monte Carlo approach to incorporate the uncertainties involved in physical, economic, and decision-making processes. Apart from the status quo option, two strategies are inflexible: building a 100year event wall immediately and building a wall and raising it in pre-determined stages over the course of a century. A flexible strategy examined is a sequence of cost-optimizing decisions to either raise or not raise the wall for a series of 20-year periods, with each decision representing a real option of a fixed period. A heuristic is used for a further flexible strategy where planners simply observe maximum sea levels during the year. If the maximum sea level comes within 0.5 meters of the top of the sea wall (initially built for a 10 -year event with a 0.5 meter safety factor), then the wall is raised in the next year to the observed maximum sea level plus 0.5 meters. With one exception, Linquiti and Vonortas conclude that there is always value to 
flexibility and the ability to delay action, as shown by the greater values of mean net present values achieved by the two flexible strategies.

In another example, Dobes (2012) infers that the combination of features in the business strategy of the legendary Australian cattle king, Sir Sidney Kidman, effectively afforded strategic flexibility in the form of real options, especially during severe region-wide droughts. Kidman's properties were invariably stocked at less than full capacity, and were generally contiguous, forming chains that straddled stock routes and watercourses in the most arid zone of central Australia. Railheads at the ends of the chains provided access to the main capital city markets, and Kidman's drovers supplied a wealth of information on competing cattle movements. Faced with a highly variable and unpredictable climate, combined with the onset of erosion and the rapid spread of rabbits, Kidman demonstrated that it is possible to adapt to environmental change on a continental scale without government assistance.

\subsubsection{Robust Decision Making}

Cost-benefit analysis utilizing real options requires specification of the probabilities for future scenarios - or at least in the form of probability distributions if using Monte Carlo methods - to identify optimal strategies. An alternative quantitative approach to incorporating uncertainty about future climate change is Robust Decision Making (RDM), which emphasizes robustness rather than optimality in decision making (e. g. Lempert et al., 2006; RANGer and GARBETt-Shiels, 2011). RDM characterizes uncertainty in terms of multiple plausible scenarios of the future produced through computer simulation of sets of probability distributions and strategies that can evolve over time in response to new information. Robust strategies are identified through regret functions that compare various strategies with the best-performing one. However, analysts still make subjective judgments about probabilities and scenarios and their relative robustness, including through techniques such as multi-criteria analysis. IBRD (2010: 37) notes that a key disadvantage of RDM is that it depends on complicated computer algorithms and software, with significant work required to make it suitable for evaluating specific projects.

\subsubsection{Flexibility and Adaptive Management}

An underlying theme discernible in the literature (e.g. Anda et al., 2009; Ingham et al., 2007) and some government agency documents (e. g. Productivity Commission, 2012) is the desirability of flexibility and adjustment to new information in the face of uncertainty. The term 'adaptive management' is sometimes used to characterize a flexible strategy that is adjusted continuously over time as circumstances change and new knowledge is acquired (e. g. ThOMPson et al., 2006). Hallegatte (2009) presents a list of five methods which can promote implicitly flexible 'uncertainty management': (i) selection of 'no regrets' strategies that produce net benefits even in the absence of climate change, (ii) preference for reversible and flexible options, (iii) incorporation of 'safety margins' in new investments, (iv) promotion of soft adaptation 
strategies, and (v) reduction of decision time horizons. Of these, at least three are inherent in the heuristic strategy analyzed by LiNQUiTI and VONORTAS (2012) where planners raise or do not raise a sea wall by a 0.5 meter safety factor above maximum sea levels each year.

\subsubsection{Insurance}

It is common to list insurance as a means of ameliorating the financial consequences of the physical impacts of climate change (e.g. Hallegate, 2009; Adger et al., 2005). Some regard the establishment of insurance-based climate risk funding as a particularly efficient way of channeling disaster relief to developing countries (e.g. LinNerooth-BAYER and Mechler, 2006).

The perspective adopted in the adaptation literature generally emphasizes the potentially catastrophic consequences of floods, hurricanes, and other disasters exacerbated by climate change. To the extent that climatic impacts will be slow-onset in nature, however, insurance may not offer an effective adaptation strategy. A key principle of insurance is that events must be fortuitous; the corollary being that pre-existing conditions or reasonably foreseeable outcomes cannot be insured. This issue does not appear to have been addressed specifically in the adaptation literature. It, therefore, remains an open question whether predicted phenomena such as gradual sea level rise, increasing temperatures, or their respective contributions to storm surge or cyclonic activity, will be treated as 'losses in progress' and therefore uninsurable. Another aspect that seems to have been ignored in the literature is that the pooling of risk within families is a form of insurance used in all societies. ERGAS (2008) surmises that intra-family insurance may even dwarf commercially provided insurance.

Efficient insurance systems require the pooling of risk for uncorrelated events, with perfect information about the risks available to both insurers and the insured. In practice, asymmetric information can generate adverse selection and moral hazard. In an adaptation context, an example of adverse selection might be the purchase of flood insurance by the owner of a property at risk, but where the insurer is not fully aware of the risk or cannot reflect it in premiums. An owner who obtains insurance may rely on the availability of compensation for flood damage and neglect to take action to limit that damage, a case of 'moral hazard' that is generally obviated by insurers imposing 'deductibles', coinsurance, or coverage exclusions that force the insured party to bear the cost of some proportion of any damage. These problems will be compounded if climate change increases the number of correlated risks, with likely increases in insurance premiums. ZeckHAuser (1995), HerweiJer et al. (2009), and KunReuther and Michel-KerJan (2009) provide reviews.

KunReuther and PAuly (2006) argue that ex post disaster relief in the USA discourages investment in protective measures before disasters, resulting in unnecessarily costly and poorly targeted assistance after the event, especially before elections. Disagreeing with the view that 'charity hazard' associated with disaster assistance reduces incentives to purchase insurance (e.g. NAESS et al., 2005; RASCHKY and 
Weck-Hannemann, 2007), they argue that people avoid even subsidized insurance because of misperceptions of risk, as well as premiums that are high relative to income. Where insurance is taken out, it is often cancelled if no claims are made within a few years, even in flood-prone areas where it is compulsory. KUNREUTHER and PAULY (2006) reject the conventional expected utility approach to determining the purchase of insurance, positing instead a sequential choice model based on the past experience of individuals. Given consumer reluctance to purchase insurance, they argue for a compulsory 'all perils' scheme with deductibles and premia reflecting individual risks, but with public subsidies to low-income residents and government-sponsored reinsurance for particularly hazardous regions such as hurricane-prone Florida. Nevertheless, they concede that more research into risk perceptions and current institutional arrangements is required.

Noting that most approaches to catastrophic loss conclude that governmental intervention is required in the form of compulsory insurance or regulation such as enhanced building codes, PrIEst (1996) compares it to private insurance markets. Compulsory participation in insurance schemes does not necessarily reduce adverse selection because governments generally do not allow discrimination between policyholders, especially those with low incomes. Because there is little focus on controlling adverse selection, government insurance programs typically encounter severe budgetary problems. Where compulsory insurance is used for potential disaster situations, compulsion also diminishes the ability to reduce risk through aggregation: declaration of an event as a disaster involves highly correlated losses in the insured pool. Government's ability to control moral hazard is also diminished to the extent that policies do not provide for deductibles, coinsurance, or coverage exclusions. Finally, governments are no better able to control moral hazard or adverse selection in incomplete insurance markets (e.g. floods, riots, and, presumably, climate change) than private insurers. They simply redistribute income under the guise of insurance programs.

\subsubsection{The "McKinsey Graph"}

The eponymous "McKinsey graph" was initially developed for greenhouse gas emission abatement policy analysis by McKinsey \& Company in 2007 (MCKINSEY \& Company, 2010), an analogous curve has also been used to suggest areas where adaptation measures would be most cost-effective. The illustrative example shown in Figure 3 is a simplified version of that provided by the Economics of Climate Adaptation Working Group (2009: Figure 19). It combines adaptation measures such as beach nourishment, roof strengthening, levees, and elevation, retrofitting or undergrounding of selected infrastructure into a single 'cost curve'. The curve implies that measures on the left side are cost-effective, while those to the right and above the cost-benefit ratio of 1.0 produce negative net economic benefits.

The McKinsey graph employs a 'damage avoided' approach to estimating economic benefits; an approach that may under- or over-estimate the extent of benefits 
(see above). Further, it is particularly misleading in presenting the cost curve as a series of total (or averaged) costs and benefits. An allocatively efficient choice between alternative adaptation measures can only be made on the basis of marginal costs (e. g. McCloskey, 1985), the so-called principle of equimarginality. Adaptation measures should be implemented until the marginal cost of each one is equal.

For example, the illustrative McKinsey graph in Figure 2 indicates that the priority for decision-makers should be to nourish beaches with sand when they erode, rather than elevating roads that are subject to flooding. However, this general rule may not hold if sand is not readily available at a particular beach or erosion occurs frequently, but local availability of construction materials makes elevation of a particular stretch of road relatively inexpensive in terms of the cost avoided.

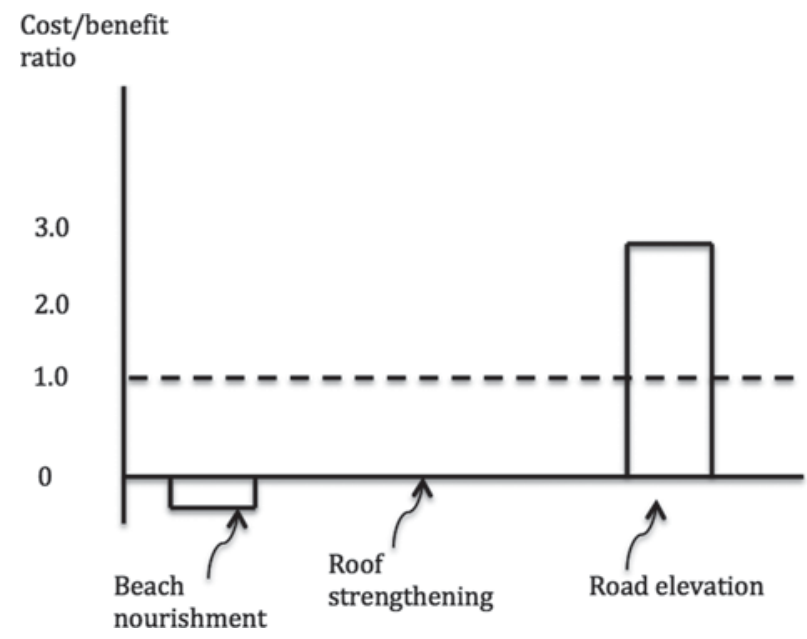

Source: Figure 2 is a simplified and purely illustrative adaptation of a typical McKinsey 'adaptation cost curve' as presented in Economics of Climate Adaptation Working Group (2009).

Figure 2: Illustrative McKinsey Adaptation Cost Curve

\subsection{Other Impacts and Responses to Climate Change}

\subsubsection{Conflict}

There is little agreement among analysts about the likely effect of future climate change on the frequency, nature, or intensity of conflict. This is partly due to varying definitions of conflict, ranging from wars between nations (ToL and WAGNER, 2010) to civil war (ZHANG et al., 2006; FAN, 2010) and a broader concept of 'security' (BARNETT, 2003) that encompasses threats such as the effect of sea level rise on low islands in the Pacific. Analysts also differ in the choice of potential explanatory fac- 
tors examined, including environmental migration due to floods or droughts, environmental degradation, loss of habitat due to sea level rise, and reduced food output due to high or low temperatures.

Little systematic, quantitative research has been published, so that there is considerable scope for conjecture and unsupported speculation. On the other hand, quantitative analysis can place undue emphasis on single or averaged variables such as the frequency of conflicts, or mean temperatures rather than extremes, while ignoring the contextual influence of other, non-climatic factors. As a result, many authors conclude (e. g. Tol and Wagner, 2010; FAn, 2010; Barnett, 2003; Hartmann, 2010) that it is necessary to be cautious about the causal links between climate change and conflict.

Reviews of conflict due to environmental and climate change issues by GLEDITSCH (1998; 2012) offer the most comprehensive critique of methodologies. There is little hard data on the effect of climate change - as distinct from particular severe weather events - on conflicts. Omission of important aspects of variables such as the political systems of states (e.g. democracy, autocracy) engaged in conflict can bias analyses. On the other hand, complex theoretical conflict models may not be testable in practice, while single-factor versions may be overly simplistic. Case studies cannot offer valid explanations of conflict without comparable control groups where no conflict has occurred. Because the future is unknown, and because of the paucity of hard data on past conflicts due to climate change, GLEDITSCH (1998: 393) points out that many authors stress the 'potential for violent conflict in the future'. In effect, they use their conjectures about the future as evidence to support current hypotheses about conflict.

Some analysts see so-called climate or environmental refugees as potentially exacerbating the potential for conflict (e. g. REUVENY, 2007: 660), either through international or internal migration. However, the migration literature is, if anything, just as speculative and subject to conjecture as the conflict literature.

\subsubsection{Migration}

Migration away from areas affected by climate change, environmental degradation, or natural disaster is an age-old form of adaptation to adverse local circumstances. Whole settlements have been abandoned throughout history as a result of environmental and other factors (Orlove, 2005; McLeman, 2011). However, there is little contemporary agreement on the typologies or definitions of so-called 'environmental' or 'climate' refugees (Dun and GEMENNE, 2008). MCLEMAN and SMIT (2006: 32) warn against considering migration as 'a simple or automatic response to a singular risk, climate-related or otherwise'. BLACK et al. (2011: 433) note that even a specific factor like drought can result in either higher or lower out-migration: if a greater proportion of the household budget is spent on food due to higher prices, less will be available to finance long-distance migration.

In reviewing studies focused on the destinations of environmental migrants, FINDLAY (2011) argues that most migrants have a strong preference for staying in their 
current location, even if available economic and social attractors elsewhere indicate potential gains to be achieved by moving. Once a decision to move has been taken, migrants' preferences are to move shorter, rather than longer distances, but those that do move will generally be those with the resources to do so, or with the social capital to be successful at their destination. Final destinations are generally selected because they are socially or culturally more accepting. Often these are urban centers rather than areas that are environmentally similar to the regions of origin.

In a detailed critique of estimates of environmental refugee numbers, GEMENNE (2011) is highly critical of the speculative manner in which projections have been produced, often with the apparent aim of attracting sensationalist media attention. Because there is no global system in place to capture refugee flows, especially within countries, figures are often highly speculative. This is compounded by lack of consensus on what constitutes an environmental refugee, including distinctions between voluntary and forced migration, displacement versus mobility, international versus internal, and voluntary versus forced movement. A major problem is that projected refugee flows have generally been estimated in a deterministic manner on the basis of populations at risk of inundation or desertification, etc., without taking into account local adaptation, internalization of impacts, or different projections of the pace of climate change. An even more serious issue is that none of the projections of refugee flows (invariably found in the non-peer reviewed grey literature) can be tested against actual numbers because of the lack of reliable statistics.

Because projections of refugee numbers have tended to rely on variables such as population affected by sea level rise, or vulnerability due to low incomes, KNIVETON et al. (2011: S34) employ agent-based modeling to isolate the effect of environmental factors on migration flows for Burkina Faso. HASSANI-MAHMOOEI and PARRIS (2012) similarly use an agent-based model with district-level data to simulate likely internal migration patterns in Bangladesh as a result of climatic shocks such as drought, floods, and cyclones. However, such models do not appear to have been applied on a global scale to simulate overall refugee flows.

Recognizing that there is still an 'open debate' about the causes of migration, Perch-Nielsen et al. (2008) nevertheless consider that many analyses propose deterministic linkages between future climate change and migration. Such analyses are often based on ostensibly 'common sense' assumptions that ignore real-life human reactions and adaptation. Instead, migration is but one of various adaptation options available in response to chains of contingent events.

\subsubsection{Other Perspectives and Issues}

Unsurprisingly, a farrago of other perspectives on adaptation exists, reflecting the special interests or conceptual frames of the proponents. PRESTON (2010) advocates regulation combined with judicial review, while MCDonald (2010: 257) raises the possibility of increased uncertainty arising from tort litigation due to different geographical circumstances. Planners and engineers tend to look to the presumed 
safety of increased standards (e. g. Standards Australia/Standards New Zealand, 2009) and tighter design guidelines (e. g. Engineers Australia, 2004; Royal Academy of Engineering, 2011). DU VAIR et al. (2002) promote the prioritized fortification of infrastructure. ButZengeiger-GeYer et al. (2011) review market mechanisms that have been advocated for mitigation, with a view to applying them to adaptation, although they concede that it would first be necessary to define a 'unit' of adaptation. JULiá and Duchin (2007) and Mendelsohn (2006) consider the potential role of international trade as an economic adjustment mechanism, SCHIPPER (2009) investigates links to the disaster management literature, and an idiosyncratic article by LIAO et al. (2012) proposes consideration of biomedical modifications such as reducing the size of humans to facilitate both the mitigation of climate change, as well as adaptation to it.

\section{References}

Ackerman, F., S. J. DeCanio, R. B. Howarth, and K. Sheeran (2009) Limitations of integrated assessment models of climate change, Climatic Change 95(3-4): 297-315.

Adger N., S. Dessai, M. Goulden, M. Hulme, I. Lorenzoni, D. R. Nelson, L. O. Naess, J. Wolf, and A. Wreford (2009) Are there social limits to adaptation to climate change? Climatic Change 93(3-4): 335-354.

Adger W. N., N. W. Arnell, and E. L. Tompkins (2005) Successful adaptation to climate change across scales, Global Environmental Change 15(2): 77-86.

Agrawala, S. and S. Fankhauser (2008) Economic Aspects of Adaptation to Climate Change: Costs, Benefits and Policy Instruments, OECD, Paris.

Aldy, J. E. (2006) Per capita carbon dioxide emissions: convergence or divergence? Environmental and Resource Economics 33(4): 533-555.

Aldy, J. E. and R. N. Stavins (2007) Architectures for Agreement, Cambridge University Press.

Amram, M. and N. Kulatilaka (1999) Real Options: Managing Strategic Investments in an Uncertain World, Harvard Business School Press, Boston MA.

Anda, J., A. Golub, and E. Strukova (2009) Economics of climate change under uncertainty: benefits of flexibility, Energy Policy 37: 1345-1355.

Anjum Z., P. J. Burke, R. Gerlagh, and D. I. Stern (2014) Modeling the emissionsincome relationship using long-run growth rates, CCEP Working Papers 1403.

Arrhenius, S. (1896) On the influence of carbonic acid in the air upon the temperature of the ground, Philosophical Magazine Series 5 41(April): 237-276.

Ausubel, J. H. and W. D. Nordhaus (1983) A review of estimates of future carbon dioxide emissions, in T. F. Malone (ed.) Changing Climate: Report of the Carbon Dioxide Assessment Committee, National Academy Press, Washington DC. Chapter 2.2, 153185.

BARnett, J. (2003) Security and climate change, Global Environmental Change 13: 7-17.

Barnett, J. and S. O’Neill (2010) Maladaptation, Global Environmental Change 20(2): 211-213.

BArrett, S. (1990) The problem of global environmental protection, Oxford Review of Economic Policy 6(1): 68-79. 
Beg, N., J. C. Morlot, O. Davidion, Y. Afrane-Okesse, L. Tyani, F. Denton, Y. Sokona, J. P. Thomas, E. L. La Rovere, J. K. Parikh (2002) Linkages between climate change and sustainable development, Climate Policy 2: 129-144.

Berkhout, F. (2005) Rationales for adaptation in EU climate change policies, Climate Policy 5(3): 377-391.

Black, F. and M. Scholes (1973) The pricing of options and corporate liabilities, Journal of Political Economy 81(3): 637-654.

Black, R., D. Kniveton, and K. Schmidt-Verkerk (2011) Migration and climate change: towards an integrated assessment of sensitivity, Environment and Planning A 43 (2): 431-450.

Borison, A. (2005) Real options analysis: where are the emperor's clothes? Journal of Applied Corporate Finance 17(2): 17-31.

Bosello, F., C. Carraro, and E. De Cian (2010) Climate policy and the optimal balance between mitigation, adaptation and unavoided damage, Climate Change Economics 1: 71-92.

Boyd, O. (2012) China's energy reform and climate policy: the ideas motivating change, CCEP Working Papers 1205.

Braganza, K. (2011) The greenhouse effect is real: here's why, The Conversation 14 June.

Brock, W. A. and M. S. TAYLOR (2010) The green Solow model, Journal of Economic Growth 15: 127-153.

Burton, I., S. Huq, B. Lim, O. Pilifisova, and E.L. Schipper (2002) From impacts assessment to adaptation priorities: The shaping of adaptation policy, Climate Policy 2 (2): $145-159$.

Butzengeiger-Geyer, S., A. Michaelowa, M. Koehler, and M. Stadelmann (2011) Market mechanisms for adaptation to climate change - lessons from mitigation and a pathway to implementation, CIS Working Paper 71-2011, Center for Comparative and International Studies, University of Zurich.

Callaway, J. M. (2004) Adaptation benefits and costs: are they important in the global policy picture and how can we estimate them? Global Environmental Change 14(3): 273282.

Callendar, G. S. (1938) The artificial production of carbon dioxide and its influence on temperature, Quarterly Journal of the Royal Meteorological Society 64: 223-240.

Canadell, J. G., C. Le Quéré, M. R. Raupach, C. B. Field, E. T. Buitenhuis, P. Ciais, T. J. Conway, N. P. Gillett, R. A. Houghton, and G. Marland (2007) Contributions to accelerating atmospheric $\mathrm{CO}_{2}$ growth from economic activity, carbon intensity, and efficiency of natural sinks, Proceedings of the National Academy of Sciences 104(47): 18866-18870.

CARson, R. T. (2010) The environmental Kuznets curve: seeking empirical regularity and theoretical structure, Review of Environmental Economics and Policy 4(1): 3-23.

Chen, X. and Y. Zong (1999) Major impacts of sea-level rise on agriculture in the Yangtze delta area around Shanghai, Applied Geography 19: 69-84.

Cooley, D. (2009) Extreme value analysis and the study of climate change. A commentary on Wigley 1988, Climatic Change 97: 77-83.

Copeland, T. and V. Antikarov (2001) Real Options: A Practitioner's Guide, Texere, New York.

Cox, L.A. (2009) What's wrong with hazard-ranking systems? An expository note, Risk Analysis 29(7): 940-948. 
Crompton, R. P. and K. J. McAneney (2008) Normalised Australian insured losses from meteorological hazards: 1967-2006, Environmental Science \& Policy 11: 371-378.

Curry, J. (2011) Reasoning about climate uncertainty, Climatic Change 108: 723-732.

D’Arge, R. C. et al. (1975) Economic and Social Measures of Biologic and Climatic Change, U.S. Department of Transportation.

D'Arge, R. C., W. D. Schulze, and D. S. Brookshire (1982) Carbon dioxide and intergenerational choice, American Economic Review 72(2): 251-256.

Darwin, R. F. and R. S. J. Tol (2001) Estimates of the economic effects of sea level rise, Environmental and Resource Economics 19(2): 113-129.

de Bruin, K., R. B. Dellink, A. Ruijs, L. Bolwidt, A. van Buuren, J. Graveland, R. S. de Groot, P. J. Kuikman, S. Reinhard, R. P. Roetter, V. C. Tassone, A. Verhagen, and E. C. Van Ierland (2009) Adapting to climate change in The Netherlands: an inventory of climate adaptation options and ranking of alternatives, Climatic Change 95(1-2): 23-45.

Dietz, S. and D. J. Maddison (2009) New frontiers in the economics of climate change, Environmental and Resource Economics 43: 295-306.

Dixit, A. K. and R. S. PINDyck (1994) Investment under Uncertainty, Princeton University Press, New Jersey.

Dobes, L. (2010) Notes on applying 'real options' to climate change adaptation measures, with examples from Vietnam, CCEP Working Papers 7.10.

Dobes, L. (2012) Sir Sidney Kidman: Australia's cattle king as a pioneer of adaptation to climatic uncertainty, Rangeland Journal, 34(1): 1-15.

Dobes, L. and J. BenNetT (2009) Multi-criteria analysis: 'good enough' for government work? Agenda 16(3): 7-30.

DodA, B. (2014) Evidence on business cycles and $\mathrm{CO}_{2}$ emissions, Journal of Macroeconomics 40: 214-227.

Doria, M. de F., E. Boy, E. L. Tompkins, and W. N. Adger (2009) Using expert elicitation to define successful adaptation to climate change, Environmental Science \& Policy 12(7): 810-819.

Dun, O. and F. Gemenne (2008) Defining 'environmental migration', Forced Migration Review 31: 10-11.

duVair, P., D. Wickizer, and M. J. Burer (2002) Climate change and the potential implications for California's transportation system, in: The Potential Impacts of Climate Change on Transportation: Workshop Summary and Proceedings, U.S. DOT (Center for Climate Change and Environmental Forecasting) in cooperation with U.S. EPA, U.S DEA, U.S. GCRP.

Economics of Climate Adaptation Working Group (2009) Shaping climate-resilient development: A framework for decision-making, Climate Works Foundation, Global Environment Facility, European Commission, McKinsey \& Company, The Rockefeller Foundation, United Nations Environment Programme, Standard Chartered Bank and Swiss Re.

Edmonds, J. and J. Reilly (1983a) A long-term global energy-economic model of carbon dioxide release from fossil fuel use, Energy Economics 5(2): 74-88.

Edmonds, J. and J. Reilly (1983b) Global energy and $\mathrm{CO}_{2}$ to the year 2050, The Energy Journal 4(3): 21-48.

Ehrlich, P. R. and J. P. Holdren (1971) Impact of population growth, Science 171 (3977): 1212-1217. 
Ellerman, A. D. and B. K. Buchner (2007) The European Union emissions trading scheme: origins, allocation, and early results, Review of Environmental Economics and Policy 1: 66-87.

Engineers Australia (2004) Guidelines for Responding to the Effects of Climate Change in Coastal and Ocean Engineering, Canberra.

ERDA, L. (1996) Agricultural vulnerability and adaptation to global warming in China, Water Air and Soil Pollution 92: 63-73.

Ergas, H. (2008) Shelter from the storm: reflections on the 'risk society', Quadrant January/February: 11-21.

FAN, K.-W. (2010) Climatic change and dynastic cycles in Chinese history: a review essay, Climatic Change 101: 565-573.

Fankhauser S., J. B. Smith, and R. S. J. Tol (1999) Weathering climate change: some simple rules to guide adaptation decisions, Ecological Economics 30: 67-78.

Findlay, A. M. (2011) Migrant destinations in an era of environmental change, Global Environmental Change 21S: S50-S58.

Fourier, J. B. (1827) Memoire sur les temperatures du globe terrestre et des espaces plan- etaires, Mem. Acad. R. Sci. Inst. France 7: 569-604.

Fuessel, H.-M. (2009a) Ranking of national-level adaptation options: an editorial comment, Climatic Change 95(1-2): 47-51.

Fuessel, H.-M. (2009b) Review and quantitative analysis of indices of climate change exposure, adaptive capacity, sensitivity, and impacts, Background Note to World Development Report 2010: Development and Climate Change, Potsdam Institute for Climate Impact Research.

Fuessel, H.-M. and R. J. T. KLeIN (2006) Climate change vulnerability assessments: an evolution of conceptual thinking, Climatic Change 75: 301-329.

Garnaut, R. (2008) The Garnaut Climate Change Review, Cambridge University Press. Chapter: Introduction (pages xvii-xxxiv)

Garnaut, R., S. Howes, F. Jotzo, and P. Sheehan (2008) Emissions in the Platinum Age: the implications of rapid development for climate-change mitigation, Oxford Review of Economic Policy 24(2): 377-401.

Gemenne, F. (2011) Why the numbers don't add up: a review of estimates and people displaced by environmental changes, Global Environmental Change 21 (Supplement 1), December: S41-S49.

Gersonius, B., R. Ashley, A. Pathirana, and C. Zevenbergen (2013) Climate change uncertainty: building flexibility into water and flood risk infrastructure, Climatic Change 116: 411-423.

Giorgi, F. (2005) Climate change prediction, Climatic Change 73: 239-265.

Gleditsch, N. P. (2012) Whither the weather? Climate change and conflict, Journal of Peace Research 49(1): 3-9.

Gleditsch, N. P. (1998) Armed conflict and the environment: A critique of the literature, Journal of Peace Research 35(3): 381-400.

Gollier, C. (2012) Pricing the Planet's Future: The Economics of Discounting in an Uncertain World, Princeton University Press.

Goulder, L. H. and R. C. Williams (2012) The choice of discount rate for climate change policy evaluation, Climate Change Economics 3(4): 1250024-1-1250024-18.

Griliches, Z. (1992) The search for R\&D spillovers, NBER Working Paper 3768. 
Groosman, B., N. Z. Muller, and E. O’Neill-Toy (2011) The ancillary benefits from climate policy in the United States, Environmental and Resource Economics 50(4): 585-603.

Grossman, G. M. and A. B. Krueger (1991) Environmental impacts of a North American Free Trade Agreement, NBER Working Paper 3914.

GrubB, M. (1995) Seeking fair weather: ethics and the international debate on climate change, International Affairs 71(3): 463-496.

Grübler, A., N. NAKicÉnOvic, and D. G. Victor (1999) Dynamics of energy technologies and global change, Energy Policy 27: 247-280.

Hahn, M., A. M. Riederer, and O. Foster (2009) The livelihood vulnerability index: a pragmatic approach to assessing risks from climate variability and change - a case study in Mozambique, Global Environmental Change 19: 74-88.

Hallegatte, S. (2009) Strategies to adapt to an uncertain climate change, Global Environmental Change, 19(2): 240-247.

Hallegatte, S., J-C. Hourcade and P. Ambrosi (2007) Using climate analogues for assessing climate change economic impacts in urban areas, Climatic Change 82(1-2): $47-60$.

Hanemann, W. M. (2000) Adaptation and its measurement, Climatic Change 45(3-4): 571-581.

Harmeling, S. and D. EcKstein (2012) Global Climate Risk Index 2013, Germanwatch, Bonn.

Hartmann, B. (2010) Rethinking climate refugees and climate conflict: rhetoric, reality and the politics of policy discourse, Journal of International Development 22: 233-246.

Hassani-Mahmooei, B. and B. W. Parris (2012) Climate change and internal migration patterns in Bangladesh: an agent-based model, Environment and Development Economics 17(6): 763-780.

Held, I. M. and B. J. Soden (2000) Water vapor feedback and global warming, Annual Review of Energy and the Environment 25: 441-475.

Henriques, S. T., and A. Kander (2010) The modest environmental relief resulting from the transition to a service economy, Ecological Economics 70(2): 271-282.

Hertzler, G. (2007) Adapting to climate change and managing climate risks by using real options, Australian Journal of Agricultural Research 58: 985-992.

Herweijer, C., N. Ranger, and R. E. T. Ward (2009) Adaptation to climate change: threats and opportunities for the insurance industry, The Geneva Papers 34: 360-380.

Heutel, G. (2012) How should environmental policy respond to business cycles? Optimal policy under persistent productivity shocks, Review of Economic Dynamics 15(2): 244-264.

Hitz, S. and J. Sмiтh (2004) Estimating global impacts from climate change, Global Environmental Change 14(3): 201-218.

Holtz-Eakin, D. and T. M. Selden (1995) Stoking the fires? $\mathrm{CO}_{2}$ emissions and economic growth, Journal of Public Economics 57(1): 85-101.

Hope, C., J. Anderson, and P. Wenman (1993) Policy analysis of the greenhouse effect: an application of the PAGE model, Energy Policy 21(3): 327-338.

Houghton, R. A. (2003) Revised estimates of the annual net flux of carbon to the atmosphere from changes in land use and land management 1850-2000, Tellus 55B: 378-390.

Houghton, R. A. (2010) How well do we know the flux of $\mathrm{CO}_{2}$ from land use change? Tellus 62B: 337-351. 
Howden, S. M., J.-F. Soussana, F. N. Tubiello, N. Chhetri, M. Dunlop, and H. Meinke (2007) Adapting agriculture to climate change, Proceedings of the National Academy of Sciences 104(50): 19691-29696.

Hunter, J. (2010) Estimating sea level extremes under conditions of uncertain sea-level rise, Climatic Change 99: 331-350.

Ingham, A., J. MA, and A. Ulph (2007) Climate change, mitigation and adaptation with uncertainty and learning, Energy Policy 35: 5354-5369.

International BANK For Reconstruction AND DeVelopment (IBRD)/World Bank (2010) Economic Evaluation of Climate Change Adaptation Projects: Approaches for the Agricultural Sector and Beyond, The World Bank, Washington.

IPCC (2012) Managing the Risks of Extreme Events and Disasters to Advance Climate Change Adaptation. A Special Report of Working Groups I and II of the Intergovernmental Panel on Climate Change [C. B. Field, V. Barros, T. F. Stocker, D. Qin, D. J. Dokken, K. L.

Jabeen, H., C. Johnson, and A. Allen (2010) Built-in resilience: learning from grassroots coping strategies for climate variability, Environment and Urbanization 22(2): 415-431.

Jaffe, A. B., R. G. Newell, and R. N. Stavins (2005) A tale of two market failures: technology and environmental policy, Ecological Economics 54: 164-174.

Janssen, M. A., M. L. Schoon, W. Ke, and K. Boerner (2006) Scholarly networks on resilience, vulnerability and adaptation within the human dimensions of global environmental change, Global Environmental Change 16: 240-252.

JoNES, R. N. (2000) Managing uncertainty in climate change projections - issues for impact assessment. An editorial comment, Climatic Change 45(3-4): 403-419.

Jotzo F., P. J. Burke, P. J. Wood, A. Macintosh, and D. I. Stern (2012) Decomposing the 2010 global carbon dioxide emissions rebound, Nature Climate Change 2(4): 213-214.

Julia, R. and Duchin F. (2007) World trade as the adjustment mechanism of agriculture to climate change, Climatic Change, 82(3-4): 393-409.

Kander, A. and M. Lindmark (2006) Foreign trade and declining pollution in Sweden: a decomposition analysis of long-term structural and technological effects, Energy Policy 34(13): 1590-1599.

Kander, A., M. Jiborn, D. D. Moran, and T. O. Wiedmann (2015) National greenhouse-gas accounting for effective climate policy on international trade, Nature Climate Change.

Kates, R. W. (1997) Climate change 1995: impacts, adaptations, and mitigation, Environment 39(9): 29-33.

KAtz, R.W. and Brown, B. G. (1992) Extreme events in a changing climate: Variabilitiy is more important than averages, Climatic Change, 21(3): 289-302.

Kaya, Y. and K. YoковоRi (1997) Environment, Energy, and Economy: Strategies for Sustainability, United Nations University Press.

KeEling, C. D. (1960) The concentration and isotopic abundances of carbon dioxide in the atmosphere, Tellus 12(2): 200-203.

Keeling, C. D., R. B. Bacastow, A. E. Bainbridge, C. A. Ekdahl, P. R. Guenther, L. S. Waterman, and J. F. S. Chin (1976) Atmospheric carbon dioxide variations at Mauna Loa observatory, Hawaii, Tellus 28(6): 538-551.

Kennedy, A. B. (2013) China's search for renewable energy: pragmatic techno-nationalism, Asian Survey 53(5): 909-930. 
Kinney, P. L., M. S. O’Neill, M. L. Bell, and J. Schwartz (2008) Approaches for estimating effects of climate change on heat-related deaths: challenges and opportunities, Environmental Science and Policy 11: 87-96.

Klein, J. T. and D. C. MAciver (1999) Adaptation to climate variability and change: methodological issues, Mitigation and Adaptation Strategies for Global Change 4(3-4): 189-198.

Kniveton, D., C. Smith, and S. Wood (2011) Agent-based model simulations of future changes in migration flows for Burkina Faso, Global Environmental Change Supplement 1: S34-S40.

Knutti, R. and G. C. Hegerl (2008) The equilibrium sensitivity of the Earth's temperature to radiation changes, Nature Geoscience 1: 735-743.

Kovats, S. and R. Akhtar (2008) Climate, climate change and human health in Asian cities, Environment and Urbanization 20: 165-175.

Kunnas, J. (2011) How to proceed after Copenhagen, Electronic Green Journal 1(31).

Kunreuther, H. C. and E. O. Michel-KerJan (2009) At War with the Weather, The MIT Press, Cambridge, MA.

Kunreuther, H. C. and M. Pauly (2006) Rules rather than discretion: lessons from Hurricane Katrina, Journal of Risk and Uncertainty 33: 101-116.

Kurukulasuriya, P. and R. Mendelsohn (2008) Crop switching as a strategy for adapting to climate change, African Journal of Agricultural and Resource Economics 2(1): $105-125$.

Lange, A., A. Löschel, C. Vogt, and A. Ziegler (2010) On the self-interested use of equity in international climate negotiations, European Economic Review 54(3): 359-375.

Laube, W., B. Schraven, and M. Awo (2012) Smallholder adaptation to climate change: dynamics and limits in Northern Ghana, Climatic Change 111: 753-774.

Leggett, J., W. J. Pepper, and R. J. Swart (1992) Emissions scenarios for the IPCC: an update, in J. T. Houghton, B. A. Callander, and S. K. Varney (eds.) Climate Change 1992: The Supplementary Report to the IPCC Scientific Assessment, Cambridge University Press. Chapter A3, 69-96.

Lempert, R. J., D. G. Groves, S. W. Popper, and S. C. Bankes (2006) A general analytic method for generating robust strategies and narrative scenarios, Management Science 52(4): 514-528.

Leroux, A. and L. Crase (2010) Advancing water trade: a preliminary investigation of urban-irrigation options contracts in the Ovens Basin, Victoria, Australia Economic Papers 29(3): 251-266.

Levinson, A. (2010) Offshoring pollution: is the United States increasingly importing polluting goods? Review of Environmental Economics and Policy 4(1): 63-83.

Liao, S. M., A. SandberG, and R. Roache (2012) Human engineering and climate change, Ethics, Policy and Environment 15(2): 206-221.

Linnerooth-Bayer, J. and R. Mechler (2006) Insurance for assisting adaptation to climate change in developing countries: a proposed strategy, Climate Policy 6(6): 621636.

Linquiti, P. and N. Vonortas (2012) The value of flexibility in adapting to climate change: A real options analysis of investments in coastal defense, Climate Change Economics 3(2): 1-15. 
LiU, C., D. Golding, and G. Gong (2008) Farmers' coping response to the low flows in the lower Yellow River: a case study of temporal dimensions of vulnerability, Global Environmental Change 18: 543-553.

Ludwig, F., S. P. Milroy, and S. Asseng (2009) Impacts of recent climate change on wheat production systems in Western Australia, Climatic Change 92(3-4): 495-517.

Luehrman, T. A. (1998) Investment opportunities as real options: getting started on the numbers, Harvard Business Review July-August: 51-67.

Maybee, B. M., D. J. Packey, and R. D. Ripple (2012) Climate change policy: the effect of real options valuation on the optimal mitigation-adaptation balance, Economic Papers 31(2): 216-224.

McClintock, A. (2010) Investment in Irrigation Technology: Water Use Change, Public Policy and Uncertainty, Technical Report no. 01/10, Cooperative Research Centre for Irrigation Futures.

MCCloskey, D. (1985) The applied theory of price, $2^{\text {nd }}$ ed., Macmillan, USA.

McDonald, J. (2010) Paying the price of adaptation: compensation for climate change impacts, in T. Bonyhady, A. Macintosh, and J. McDonald (eds.) Adaptation to Climate Change. Law and Policy, Federation Press, Sydney. Chapter 10, 234-264

McKibisin, W. and P. Wilcoxen (2002) The role of economics in climate change policy, Journal of Economic Perspectives, 16(2): 107-129

MCKINSEY \& COMPANY (2010) Impact of the financial crisis on carbon economics: Version 2.1 of the global greenhouse gas abatement curve, McKinsey \& Company.

McLeman, R. A. (2011) Settlement abandonment in the context of global environmental change, Global Environmental Change 21S: S108-S120.

McLeman, R. A. and B. Smit (2006) Migration as an adaptation to climate change, Climatic Change 76: 31-53.

McMichael, A., R. A. Woodruff, and S. Hales (2006) Climate change and human health: present and future risks, The Lancet 367: 859-869.

Mearns, L. O., M. Hulme, T. R. Carter, R. Leemans, M. Lal, P. Whetton, L. Hay, N. Jones, R. Katz, J. Smith, and R. Wilby (2001) Climate scenario development, in R. Houghton et al. Climate Change 2001: The Scientific Basis. Contribution of Working Group I to the Third Assessment Report of the Intergovernmental Panel on Climate Change, Cambridge University Press. Chapter 13.

Mendelsohn, R. (2000) Efficient adaptation to climate change, Climatic Change 45(3-4): 583-600.

Mendelsohn, R. (2006) The role of markets and governments in helping society adapt to a changing climate, Climatic Change, 78(1): 203-215.

Mendelsohn, R., W. D. Nordhaus, and D. Shaw (1994) The impact of global warming on agriculture: a Ricardian analysis, American Economic Review 84(4): 753-771.

Mendelsohn, R., W. Morrison, M. E. Schlesinger, and N. G. Andronova (2000) Country-specific market impacts of climate change, Climatic Change 45(3-4): $553-569$.

Mercer, J. (2010) Disaster risk reduction or climate change adaptation: are we reinventing the wheel? Journal of International Development 22: 247-264.

Michelsen, A. M. and R. A. Young (1993) Optioning agricultural water rights for urban water supplies during drought, American Journal of Agricultural Economics 75(4): 1010-1020. 
Miller, F., J. Osbahr, E. Boyd, F. Thomalla, S. Bharwani, G. Ziervogel, B. Walker, J. Birkmann, S. van der Leeuw, J. Rockstrom, J. Hinkel, T. DownING, C. Folke, and D. Nelson (2010) Resilience and vulnerability: complementary or conflicting concepts, Ecology and Society 15(3): 11.

Moss, D. (2002) When All Else Fails: Government as the Ultimate Risk Manager, Harvard University Press.

Moss, R. H., J. A. Edmonds, K. A. Hibbard, M. R. Manning, S. K. Rose, D. P. van Vuuren, T. R. Carter, S. Emori, M. Kainuma, T. Kram, G. A. Meehl, J. F. B. Mitchell, N. Nakicenovic, K. Riahi, S. J. Smith, R. J. Stouffer, A. M. Thomson, J. P. Weyant, and T. J. Wilbanks (2010) The next generation of scenarios for climate change research and assessment, Nature 463: 747-756.

Naess, L. O., G. Bang, S. Eriksen, J. Vevatne (2005) Institutional adaptation to climate change: flood responses at the municipal level in Norway, Global Environmental Change 15: 125-138.

Nakićenović, N. et al. (2000) Special Report on Emissions Scenarios: A Special Report of Working Group III of the Intergovernmental Panel on Climate Change, Cambridge University Press.

Nordhaus, W. D. (1993) Optimal greenhouse-gas reductions and tax policy in the 'DICE' model, American Economic Review 83: 313-317.

Nordhaus, W. D. and G. W. Yohe (1983) Future paths of energy and carbon dioxide emissions, in T. F. Malone (ed.) Changing Climate: Report of the Carbon Dioxide Assessment Committee, National Academy Press, Washington DC. Chapter 2.1, 87-152.

Nordhaus, W. D. and Z. YANG (1996) A regional dynamic general-equilibrium model of alternative climate-change strategies, American Economic Review 86: 741-65.

Nordvik, V. and K. R. Liso (2004) A primer on the building economics of climate change, Construction Management and Economics 22: 765-775.

Oppenheimer, M. (2005) Defining dangerous anthropogenic interference: the role of science, the limits of science, Risk Analysis 25(6): 1399-1407.

Orlove, B. (2005) Human adaptation to climate change: a review of three historical cases and some general perspectives, Environmental Science \& Policy 8: 589-600.

Patz, J. A, D. Campbell-Lendrum, T. Holloway, and J. A. Foley (2005) Impact of regional climate change on human health, Nature 438: 310-317.

Perch-Nielsen, S. L. (2010) The vulnerability of beach tourism to climate change - an index approach, Climatic Change 100: 579-606.

Perch-Nielson, S. L., M. Baettig, and D. Imboden, (2008) Exploring the link between climate change and migration, Climatic Change 91(3-4): 375-393.

Peters, G. P. and E. G. Hertwich (2008) $\mathrm{CO}_{2}$ embodied in international trade with implications for global climate policy, Environmental Science and Technology 42(5): 1401-1407.

Peters, G. P., G. Marland, C. Le Quéré, T. Boden, J. G. Canadell, and M. R. RAupaCH (2012) Rapid growth in $\mathrm{CO}_{2}$ emissions after the 2008-2009 global financial crisis, Nature Climate Change 2: 2-4.

Peterson, T. C., W. M. Connolley, and J. Fleck (2008) The myth of the 1970s global cooling scientific consensus, Bulletin of the American Meteorological Society September: $1325-1337$.

Pielke, R. (Jr), G. Prins, S. Rayner, and D. Sarewitz (2007) Lifting the taboo on adaptation, Nature 445: 597-598. 
Pielke, R. A. (JR) and C. W. Landsea (1998) Normalized hurricane damages in the United States: 1935-95, Weather and Forecasting 13: 621-631.

Pindyck, S. (2013) Climate change policy: what do the models tell us? Journal of Economic Literature 51(3): 860-872.

Plass, G. N. (1956a) The carbon dioxide theory of climatic change, Tellus 8(2): 140-154.

Plass, G. N. (1956b) Carbon dioxide and the climate, American Scientist (44): 302-316.

Plassmann, F. and N. Khanna (2006) Preferences, technology, and the environment: understanding the environmental Kuznets curve hypothesis, American Journal of Agricultural Economics 88(3): 632-643.

Pollitt, C. (2010) Simply the best? The international benchmarking of reform and good governance, in J. Pierre and P. W. Ingraham (eds.) Comparative Administrative Change and Reform, McGill-Queen's University Press, Montreal. Chapter 4.

Preston, B. (2010) The role of courts in relation to adaptation to climate change, in $\mathrm{T}$. Bonyhady, A. Macintosh, and J. McDonald (eds.) Adaptation to Climate Change. Law and Policy, Federation Press, Sydney. Chapter 7.

Priest, G. L. (1996) The government, the market, and the problem of catastrophic loss, Journal of Risk and Uncertainty 12(2-3): 219-237.

Productivity Commission (2012) Barriers to Effective Climate Change Adaptation, Inquiry Report no. 59, Canberra.

Quiggin, J. (2008) Stern and his critics on discounting and climate change: an editorial essay, Climatic Change 89: 195-205.

Ramsey, F. P. (1928) A mathematical theory of saving, Economic Journal 38: 543-559.

Ranger, N. and S. L. Garbett-Shiels (2011) How Can Decision-Makers in Developing Countries Incorporate Uncertainty about Future Climate Risks into Existing Planning and Policy-Making Processes? Centre for Climate Change Economics and Policy, Grantham Research Institute on Climate Change and the Environment: Policy Paper.

Raschky, P. A. and H. Weck-Hannemann (2007) Charity hazard - a real hazard to natural disaster insurance? Environmental Hazards 7: 321-329.

Raupach, M. R., G. Marland, P. Ciais, C. Le Quéré, J. G. Canadell, G. KlepPER, C. B. FIELD (2007) Global and regional drivers of accelerating $\mathrm{CO}_{2}$ emissions, Proceedings of the National Academy of Sciences 104(24): 10288-10293.

Reuveny, R. (2007) Climate change-induced migration and violent conflict, Political Geography 26: 656-673.

Royal ACAdemy of Engineering (2011) Infrastructure, Engineering and Climate Change Adaptation - Ensuring Services in an Uncertain Future, London.

Scheraga, J. D. and A. E. Grambsch (1998) Risks, opportunities, and adaptation to climate change, Climate Research 10(1): 85-95.

Schipper, E. L. F. (2009) Meeting at the crossroads? Exploring the linkages between climate change adaptation and disaster risk reduction, Climate and Development 1: 1630 .

Schmalensee, R., T. M. Stoker, and R. A. Judson (1998) World carbon dioxide emissions: 1950-2050, Review of Economics and Statistics 80: 15-27.

SCHWARTZ, P. (1991) The art of the long view: planning for the future in an uncertain world, Currency Doubleday, USA.

ShAFIK, N. (1994) Economic development and environmental quality: an econometric analysis, Oxford Economic Papers 46: 757-773. 
Smit, B. and J. WAndel (2006) Adaptation, adaptive capacity and vulnerability, Global Environmental Change 16(3): 282-292.

Smith, S. J., J. van Ardenne, Z. Klimont, R. J. Andres, A. Volke, S. D. Arias (2011) Anthropogenic sulfur dioxide emissions: 1850-2005, Atmospheric Chemistry and Physics 11: 1101-1116.

Sorrell, S. and J. SiJm (2003) Carbon trading in the policy mix, Oxford Review of Economic Policy 19(3): 420-437.

Standards Australia/Standards New Zealand (2009) AS/NZS ISO 31000: 2009. Risk Management - Principles and Guidelines.

STERn, D. I. (2005) Beyond the environmental Kuznets curve: diffusion of sulfur-emissions-abating technology, Journal of Environment and Development 14(1): 101-124.

STERn, D. I. (2006) Reversal in the trend of global anthropogenic sulfur emissions, Global Environmental Change 16(2): 207-220.

Stern, D. I. (2010) Between estimates of the emissions-income elasticity, Ecological Economics 69: 2173-2182.

Stern, D. I., M. S. Common, and E. B. Barbier (1996) Economic growth and environmental degradation: the environmental Kuznets curve and sustainable development, World Development 24: 1151-1160.

Stern, N. (2007) The Economics of Climate Change: The Stern Review, Cambridge University Press.

Stern, N. (2008) The economics of climate change, American Economic Review 98(2): 137.

Strazicich, Mark C. and J. A. List (2003) Are $\mathrm{CO}_{2}$ emission levels converging among industrial countries? Environmental and Resource Economics 24(3): 263-271.

Sullivan, C. and J. Meigh (2005) Targeting attention on local vulnerabilities using an integrated index approach: the example of the climate vulnerability index, Water Science and Technology 51(5): 69-78.

Thompson, A., P. Robbins, B. Sohngen, J. Arvai, and T. Koontz (2006) Economy, politics and institutions: from adaptation to adaptive management in climate change, Climatic Change 78: 1-5.

ToL, R. S. J. (1997) On the optimal control of carbon dioxide emissions: an application of FUND, Environmental Modeling \& Assessment 2(3): 151-163.

Tol, R. S. J. (2002) Estimates of the damage costs of climate change. Part 1: Benchmark estimates, Environmental and Resource Economics 21: 47-73.

Tol, R. S. J. (2005) Adaptation and mitigation: trade-offs in substance and methods, Environmental Science \& Policy 8: 572-578.

Tol, R. S. J. and S. WaGner (2010) Climate change and violent conflict in Europe over the last millennium, Climatic Change 99: 65-79.

Tol, R. S. J., S. Fankhauser, and J. B. Smith (1998) The scope for adaptation to climate change: what can we learn from the impact literature? Global Environmental Change 8(2): 109-123.

ToL, R. S. J. (2002) Estimates of the damage costs of climate change. Part I: Benchmark estimates, Environmental and Resource Economics, 21(1): 47-73.

Tri, N. H., W. N. Adger, and P. M. Kelly (1998) Natural resource management in mitigating climate impacts: the example of mangrove restoration in Vietnam, Global Environmental Change 8(1): 49-61. 
Trigeorgis, L. (1997) Real Options: Managerial Flexibility and Strategy in Resource Allocation, The MIT Press, Cambridge MA.

Tyndall, J. (1861) On the absorption and radiation of heat by gases and vapours, and on the physical connexion of radiation, absorption, and conduction, Philos. Mag. 22: 169-194, 273-285.

Ulph, A. and D. UlPh (2013) Optimal climate change policies when governments cannot commit, Environmental and Resource Economics 56: 161-176.

Urwin, K. and A. Jordan (2008) Does public policy support or undermine climate change adaptation? Exploring policy interplay across different scales of governance, Global Environmental Change 18: 180-191.

VAN Der Eng, P. (2010) Market responses to climate stress: rice in Java in the 1930s, Australian Economic History Review 50(1): 62-79.

van Vuuren, D. P., J. Edmonds, M. Kainuma, K. Riahi, A. Thomson, K. Hibbard, G. C. Hurtt, T. Kram, V. Krey, J.-F. Lamarque, T. Masui, M. Meinshausen, N. Nakicenovic, S. J. Smith, and S. K. Rose (2011) The representative concentration pathways: an overview, Climatic Change 109(1-2): 5-31.

VINCE, G. (2009) Surviving in a warmer world, New Scientist, 28 February 2009: 29-33.

VINCENT, K. (2007) Uncertainty in adaptive capacity and the importance of scale, Global Environmental Change 17(1): 12-24.

Visser, H., R. J. M. Folker, J. Hoekstra, and J. J. De Wolff (2000) Identifying key sources of uncertainty in climate change projections, Climatic Change 45: 421-457.

Vollebergh, H. R. J., B. Melenberg, and E. Dijkgraaf (2009) Identifying reducedform relations with panel data: the case of pollution and income, Journal of Environmental Economics and Management 58(1): 27-42.

Wagner, M. (2008) The carbon Kuznets curve: a cloudy picture emitted by bad econometrics, Resource and Energy Economics 30: 388-408.

Weitzman, M. L. (2009) On modeling and interpreting the economics of catastrophic climate change, Review of Economics and Statistics, 91: 1-19.

Westerlund, J. and S. A. BAsher (2008) Testing for convergence in carbon dioxide emissions using a century of panel data, Environmental and Resource Economics 40: 109120.

Weyant, J. P. (1993) Costs of reducing global carbon emissions, Journal of Economic Perspectives 7(4): 27-46.

Wigley, T. M. L. (2009) The effect of changing climate on the frequency of absolute extreme events, Climatic Change 97: 67-76.

Wood, P. J. (2011) Climate change and game theory, Annals of the New York Academy of Sciences 1219: 153-170.

York, R. (2012) Asymmetric effects of economic growth and decline on $\mathrm{CO}_{2}$ emissions, Nature Climate Change 2(11): 762-764.

Zeckhauser, R. (1995) Insurance and catastrophes, The Geneva Papers on Risk and Insurance Theory 20: 157-175.

Zhang, D. D., C. Y. Jim, G. C.-S. Lin, Y.-Q. He, J. J. Wang, and H. F. Lee (2006) Climatic change, wars and dynastic cycles in China over the last millennium, Climatic Change 76: 459-477.

Zhu T., J. R. Lund, M. W. Jenkins, G. F. Marques, and R. S. Ritzema (2007) Climate change, urbanization, and the optimal long-term floodplain protection, Water Resources Research 43(6): W06421. 